Check for updates

Cite this: Mater. Adv., 2022, 3,579

Received 7th July 2021,

Accepted 4th November 2021

DOI: $10.1039 / \mathrm{d} 1 \mathrm{ma} 00588$

rsc.li/materials-advances

\title{
Advancement and stabilization of copper(II) azide by the use of triazole- and tetrazole ligands - enhanced primary explosivest\$
}

\author{
Maximilian H. H. Wurzenberger, (D) Michael S. Gruhne, Marcus Lommel, \\ Norbert Szimhardt (D) and Jörg Stierstorfer (D) *
}

\begin{abstract}
Copper(I) (cupric) and copper(I) (cuprous) azide are both very powerful primary explosives with good thermal stabilities. However, both suffer from extreme sensitivities, which makes them unsuitable for any application. One brilliant concept for the synthesis of new ecofriendly, non-water soluble, and very powerful primary explosives is the assembly of ligands in the coordination sphere of copper(I) azide. Blocking of possible coordination sites through endothermic azoles allows the desensitization of copper(II) azide and leads to compounds with manageable sensitivities. 13 different nitrogen-rich tri- and tetrazole derivatives were used for the synthesis of energetic copper(I) azide complexes. The water insoluble compounds are highly promising candidates for the replacement of lead and perchlorate containing primary explosives. For the characterization, the complexes were analyzed by single crystal $X$-ray diffraction, elemental analysis (EA), infrared (IR) spectroscopy, and differential thermal analysis (DTA) measurements with heating rates of $5{ }^{\circ} \mathrm{C} \mathrm{min}^{-1}$. The bulk material purity of selected complexes was confirmed by $\mathrm{X}$-ray powder diffraction. The sensitivities toward impact (IS), friction (FS), and electrostatic discharge (ESD) of all synthesized compounds were tested and determined according to BAM (Bundesanstalt für Materialforschung und -prüfung) standards. The most promising compounds were investigated in copper shell initiation experiments with PETN as main charge.
\end{abstract}

\section{Introduction}

Metal azides are widely used chemicals in industry and daily applications. The most important one is sodium azide with an annual production of around 250 t worldwide. $^{1}$ In former times $\mathrm{NaN}_{3}$ was mainly used for the synthesis of lead azide, whereas today's utilization is widespread and ranges from a broad spectrum of organic synthesis reactions, ${ }^{2-4}$ to gas generating mixtures in airbags and bacteriostatic preservatives. ${ }^{5}$ Heavy metal azides are sensitive toward friction and impact and are used as important ingredients in detonators. ${ }^{6}$ While lead azide is still among today's most commonly utilized primary explosives in detonators or primer mixtures, other azides such as $\mathrm{AgN}_{3}, \mathrm{CuN}_{3}$, and $\mathrm{Cu}\left(\mathrm{N}_{3}\right)_{2}$ have only limited use in special applications due to their high cost (silver azide) or sensitivity (copper azides). ${ }^{7}$

Department of Chemistry, Ludwig Maximilian University of Munich, Butenandtstr. 5-13, D-81377 Munich, Germany. E-mail: jstch@cup.uni-muenchen.de; Web: http:// www.hedm.cup.uni-muenchen.de; Fax: 49-89-2180-77007

$\dagger$ Dedicated to Professor Dr Wolfgang Beck on the Occasion of his 90th Birthday. ¥ Electronic supplementary information (ESI) available. CCDC 2081730-2081740 and 2084455. For ESI and crystallographic data in CIF or other electronic format see DOI: $10.1039 / \mathrm{d} 1 \mathrm{ma} 00588 \mathrm{j}$
However, the use of lead azide has many disadvantages, which are outweighed by its advantages such as an exceptionally high thermal stability of $330^{\circ} \mathrm{C}$, high density, low cost, and many more. ${ }^{8}$ The incorporation of lead has disastrous effects to the human body. Already small amounts of lead are toxic and cause annual costs of $\$ 43.5$ billion alone in the US. ${ }^{9}$ Various studies show that chronic lead uptake is responsible for a higher autism risk, late puberty onset of 6-8 months, and a reduced IQ score up to 9 points. ${ }^{10}$ "Green" alternatives for lead containing primer mixtures were introduced onto the market in the past, using DDNP as primary explosive and tetrazene as sensitizer. ${ }^{11}$ Since then, countless numbers of diverse energetic compounds, including organic compounds, organic salts, and metastable interstitial composites have been investigated as lead replacements but none of them could be established in the market. ${ }^{12-17}$ Furthermore; the alternatives, DDNP and tetrazene, again suffer from long term stability issues or sensitivity toward light (DDNP). ${ }^{18,19}$ In the last years many efforts were put in the investigation of new energetic complex compounds (ECCs) with nitrogen-rich ligands, non-toxic or less toxic $3 \mathrm{~d}$ metal cations, and diverse anions. ${ }^{20-25}$ One outstanding class of coordination compounds consists of copper(II) azide and nitrogen rich ligands. Cuprous and cupric azide show high decompositions 

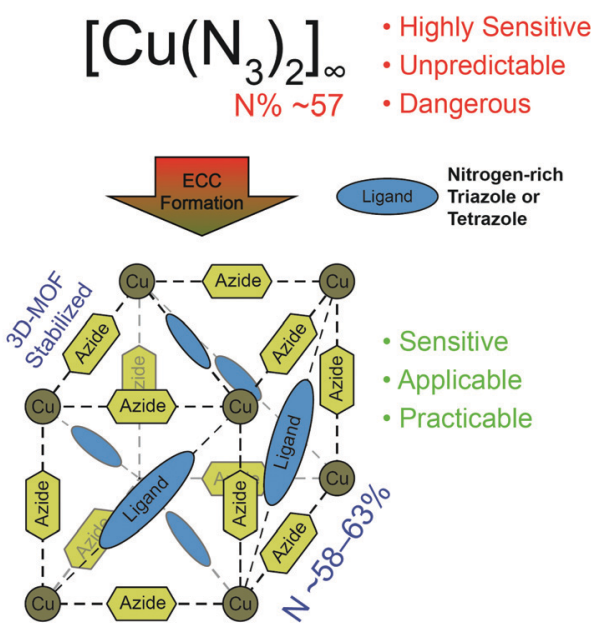

Fig. 1 Stabilization of cupric azide using nitrogen-rich triazole and tetrazole ligands.

temperatures above $200{ }^{\circ} \mathrm{C}$ but are unfortunately way too sensitive for any application. ${ }^{8}$ The latter also tends to form basic copper azides (e.g., $\mathrm{Cu}(\mathrm{OH}) \mathrm{N}_{3}$ ) under basic conditions. However, this is precisely where the ECC concept demonstrates its advantages. The aim here is to stabilize the copper azide with nitrogen-rich ligands while maintaining performance and thermal stability of neat cupric azide (Fig. 1). ${ }^{25-28}$

This has already been demonstrated with 1-methyl/1-ethyl and 1-propyl-5 $H$-tetrazole in a previous work of our group. ${ }^{29}$ The corresponding complexes are of high interest for industrial application and have been successfully incorporated into primer mixtures. ${ }^{29}$ Furthermore, several patents were issued on this topic. ${ }^{30,31}$ However, the concept of complexation of cupric azide is not new. Simple ECCs of copper(II) azide and primary amines have been known since the early 20th century and were already investigated toward their explosive character. $^{32}$ In more recent times researcher all over the world focused rather on the magnetic behaviour and the structural diversity of copper(II) azide complexes. ${ }^{33-35}$ But since the scope of coordination compounds containing nitrogen-rich ligands expanded in recent years, ranging from simple diamino alkanes to more complex triazole derivatives, the synthesis of further copper azide complexes has become feasible. ${ }^{36-38}$ However, the energetic complexes used in the previous work ${ }^{29}$ showed weaknesses especially when it comes to thermal stability. In the current study, we present a large number of enhanced copper(II) azide complexes which were stabilized and tuned with different bridging nitrogen-rich ligands, thus further increasing the compounds' thermal stability.

\section{Results and discussion}

\section{Synthesis}

In every case, literature known, or commercially available ligands were used for the preparation of the ECCs. ${ }^{39-47}$ First of all, layering experiments were performed to obtain single crystals. For this purpose, sodium azide and the respective

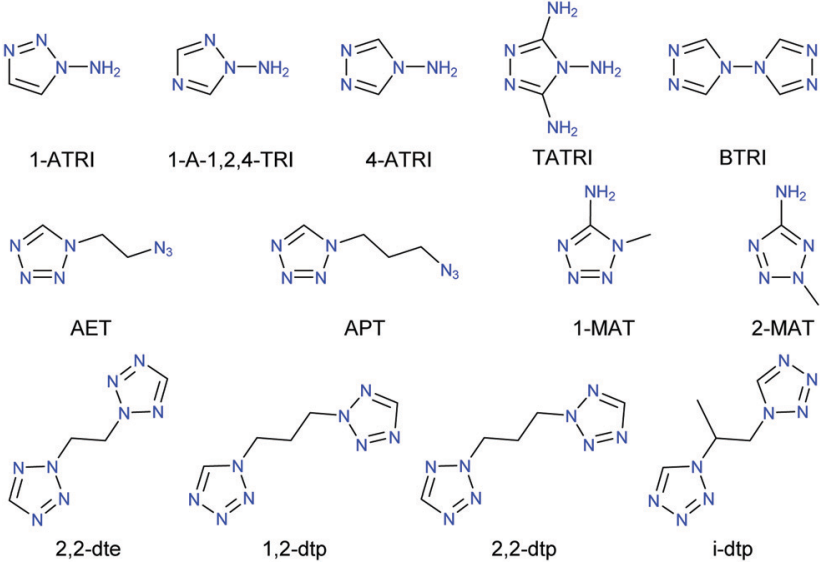

Chart 1 Overview of used nitrogen-rich ligands: 1-ATRI: 1-amino-1,2,3triazole; 1-A-1,2,4-TRI: 1-amino-1,2,4-triazole; 4-ATRI: 4-amino-1,2,4triazole; TATRI: 3,4,5-triamino-1,2,4-triazole; BTRI: 4,4'-bi(1,2,4-triazole); AET: 1 -azidoethyl-5H-tetrazole; APT: 1 -azidopropyl-5H-tetrazole; 1 -MAT: 1-methyl-5-aminotetrazole; 2-MAT: 2-methyl-5-aminotetrazole; 2,2-dte: 1,3-di(tetrazol-2-yl)ethane; 1,2-dtp: 1-(tetrazol-1-yl)-3-(tetrazol-2yl)propane; 2,2-dtp: 1,3-di(tetrazol-2-yl)propane; i-dtp: 1,2-di(tetrazol-1yl)propane.

ligand (Chart 1) were dissolved in water and carefully layered with a mixture of water and ethanol. This was followed by a solution of copper(II) chloride or nitrate in ethanol.

Using AET as a ligand afforded the two species $\mathbf{6 a}$ and $\mathbf{6 b}$. In every other case only one species was obtained during these experiments.

Subsequently, the ECCs were synthesized by the reaction of stoichiometric amounts of a soluble copper(II) salt with the respective ligand (Chart 1 and Scheme 1) in water and the addition of an aqueous solution of sodium azide, which leads to the precipitation of the complexes. For compound 5a the found elemental analysis fits well to a complex with bridging ligand. In case of the AET ligand, only species $6 \mathbf{a}$ could be isolated elemental analysis pure. Additional purity checks were performed using powder X-ray diffraction (Fig. S4-S9, ESI $\$$ ). The complexes $\mathbf{2}, \mathbf{5 b}, \mathbf{6 b}$, and $\mathbf{8}$ could not be obtained pure and were therefore not further characterized. However, this is to be expected since the formation of by-products is a general problem regarding copper azide chemistry. All complexes were obtained in good yields (44-86\%).

\section{Crystal structures}

All complexes were characterized by low temperature single crystal X-ray diffraction. Measurement and refinement data of all experiments can be found in the (Tables S1-S3, ESI $\ddagger$ ). The crystal datasets were uploaded to the CSD database and can be obtained free of charge. ${ }^{48}$ The bond lengths and angles of the coordinating ligands in the analysed complexes are in the typical range of tetrazole and triazole ligands and nearly the same as in the non-coordinating ligands. ${ }^{41-43,47,49-54}$ The ligands are therefore not part of the discussion in any of the following coordination compounds. All copper(II) azide complexes show an octahedral coordination around the central 


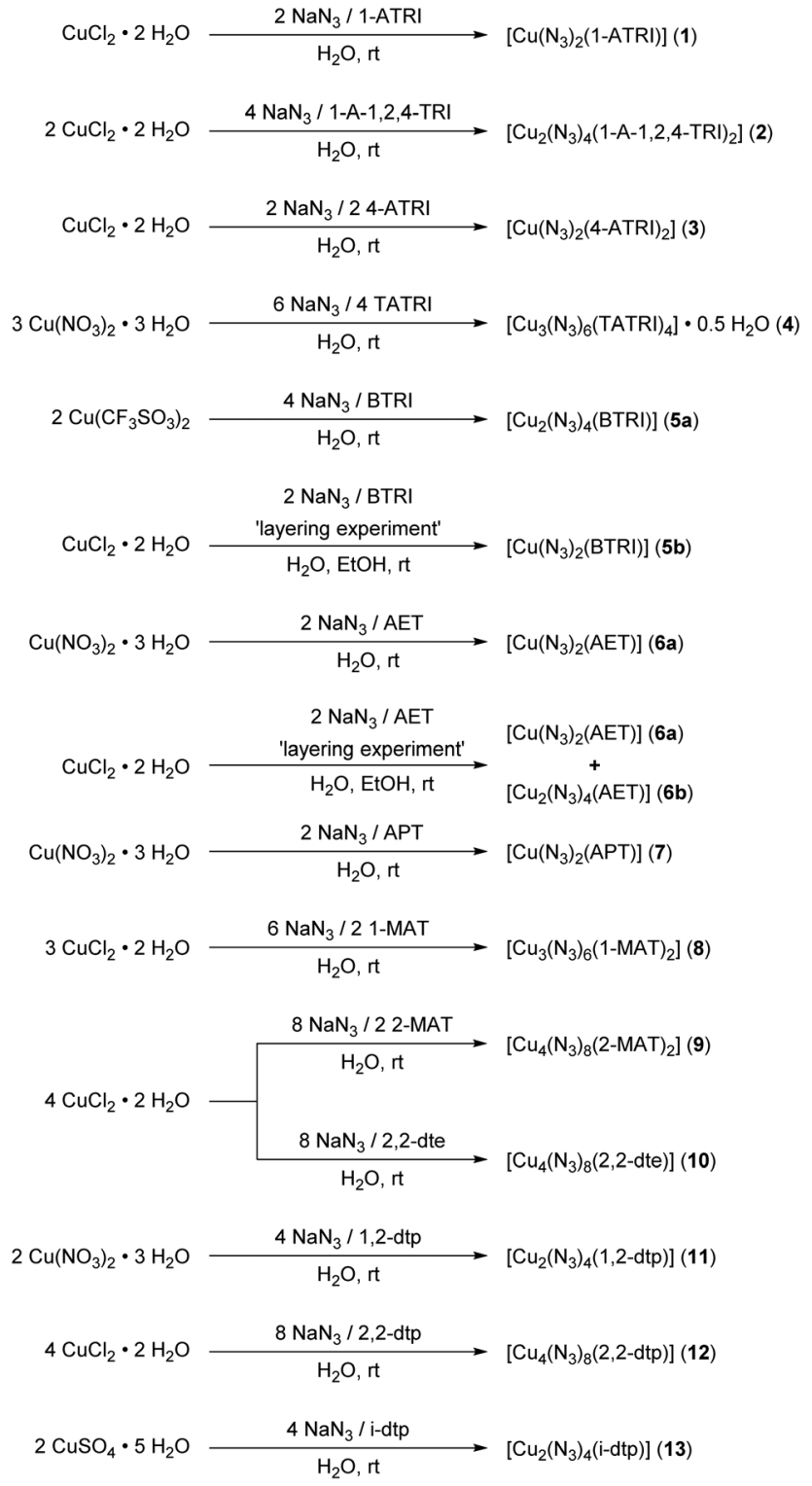

Scheme 1 Preparation of various copper(॥) azide coordination compounds based on nitrogen-rich azole ligands.

metal with a Jahn-Teller (JT) distortion along the axial coordination sphere. In addition, every complex is forming polymeric structures, whereas the type of polymerization (1D, 2D, 3D) highly depends on the combination of coordination modes of the azido and azole ligands. The investigated complexes show six different types of coordinated azide

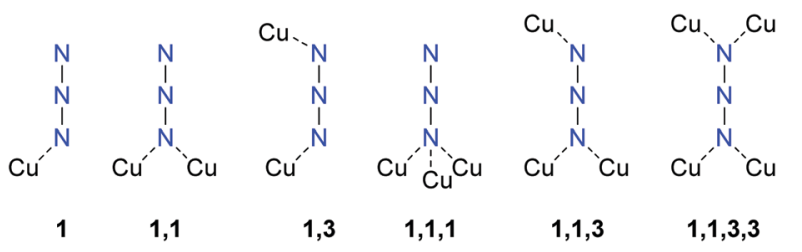

Chart 2 The six occurring coordination modes of the azide anions in compounds 1-13. moieties (Chart 2). An overview on the bridging types observed in each structure is given in Table 1.

Pure cupric azide $\left(\mathrm{Cu}\left(\mathrm{N}_{3}\right)_{2}\right)$ without any ligands shows two different types of coordinating azide anions (Chart 2: 1,1,1; $1,1,3)$ leading to very long axial Cu-N-bonds $(2.54 \AA$, $2.71 \AA)$ and the formation of 2-D polymeric layers. ${ }^{55}$ Single crystals of azide complex 11 and 13 were measured and allowed a determination of the most likely appearance of the structure. Finalizations of the datasets were not possible due to the highly disordered moieties and the related weak diffractions.

Complex compound $\mathbf{1}$ crystallizes in the form of brown rods in the monoclinic space group $P 2_{1} / c$ with four formula units per unit cell and a calculated density of $2.093 \mathrm{~g} \mathrm{~cm}^{-3}$ at $100 \mathrm{~K}$. The metal centre is coordinated (Fig. 2) by one 1-amino-1,2,3triazole molecule in equatorial position and five azide ligands. One equatorial and one axial azide are bridging to two different metals (Chart 2: 1, 1) and the remaining three anions (one axial, two equatorial) are linking between three copper(II) atoms (Chart 2: 1, 1, 1), building up linear chains with two parallel copper strands in one plane (Fig. 5).

Complex 2 possess one of the highest densities of all complexes in this work (2.226 $\mathrm{g} \mathrm{cm}^{-3}$ @ $143 \mathrm{~K}$ ) and crystallizes in the form of brown blocks in the triclinic space group $P \overline{1}$ with two formula unit per unit cell. The molecular unit is formed by two differently coordinated copper(II) cations (Fig. 3). The Cu1 cation is solely coordinated by 1,1,1 and 1,1 bridging azido ligands. This leads to the formation of strands of four copper atoms. Additionally, the $\mathrm{Cu} 2$ atoms are coordinated by aminotriazole ligands and 1,1,3 bridging azido anions. The azide moieties are linking two $\mathrm{Cu} 2$ cations, connecting the copper strands and further leading to a 2D polymeric network.

Complex 3 possess a high density $\left(1.952 \mathrm{~g} \mathrm{~cm}^{-3}\right.$ (a $\left.143 \mathrm{~K}\right)$ and crystallizes in the form of green needles in the triclinic space group $P \overline{1}$ with one formula unit per unit cell. The molecular unit consists of one copper(II) cation (Fig. 4) coordinated by two 1-amino-1,2,4-triazoles in equatorial position and four bridging azide anions. Each pair of one axial and one equatorial azide is linking between the same two copper(II) atoms (Chart 2: 1,3), which leads to the formation of 1D-chains. It is the only complex where all anions show the same bridging mode.

Comparing the polymeric structures of $\mathbf{1}$ and $\mathbf{3}$, it becomes clear that the different coordination modes of the azide moieties are leading to a double strand in the case of $\mathbf{1}$ whereas in 3 single strands are formed (Fig. 5). In both structures, intermolecular interactions between anions and triazole ligands of neighbouring chains are stabilizing the structures.

The only water containing coordination compound $\left[\mathrm{Cu}_{3}\left(\mathrm{~N}_{3}\right)_{6}(\mathrm{TATRI})_{4}\right] \cdot 0.5 \mathrm{H}_{2} \mathrm{O}(4)$ crystallizes in the form of green blocks in the triclinic space group $P \overline{1}$ with one formula unit per unit cell and a density of $1.975 \mathrm{~g} \mathrm{~cm}^{-3}$ at $123 \mathrm{~K}$. The molecular unit is built up by a trimer of copper(II) cations (Fig. 6) with two different coordination spheres. Two of the triazole ligands are linking between two copper(II) ions, which is leading to a fourfold binding of the middle cation to neutral ligands all in equatorial position. This is the highest number of azole ligands 
Table 1 Overview on selected crystallographic data of the compounds examined by single crystal X-ray diffraction

\begin{tabular}{|c|c|c|c|c|c|c|c|c|}
\hline \multicolumn{2}{|l|}{ Compound } & $\frac{\text { Space group }}{P 2_{1} / c}$ & $\frac{\rho^{a}\left[\mathrm{~g} \mathrm{~cm}^{-3}\right]}{2.093}$ & $\frac{T^{b}[\mathrm{~K}]}{100}$ & $\frac{\text { Colour }^{c}}{\text { Brown }}$ & \multicolumn{3}{|c|}{ Bridging modes of azido ligands ${ }^{d}$} \\
\hline$\left[\mathrm{Cu}_{2}\left(\mathrm{~N}_{3}\right)_{4}(1-\mathrm{A}-1,2,4-\mathrm{TRI})_{2}\right]$ & 2 & $P \overline{1}$ & 2.226 & 143 & Brown & 1,1 & $1,1,1$ & $1,1,3$ \\
\hline$\left[\mathrm{Cu}\left(\mathrm{N}_{3}\right)_{2}(4-\mathrm{ATRI})_{2}\right]$ & 3 & $P \overline{1}$ & 1.952 & 143 & Green & 1,3 & & \\
\hline$\left[\mathrm{Cu}_{2}\left(\mathrm{~N}_{3}\right)_{4}(\mathrm{BTRI})\right]$ & $5 a$ & $P 2_{1} / c$ & 2.065 & 173 & Red & 1,1 & $1,1,3$ & \\
\hline$\left[\mathrm{Cu}\left(\mathrm{N}_{3}\right)_{2}(\mathrm{AET})\right]$ & $6 a$ & $I 2 / a$ & 2.003 & 143 & Brown & 1,1 & $1,1,3$ & \\
\hline$\left[\mathrm{Cu}_{2}\left(\mathrm{~N}_{3}\right)_{4}(\mathrm{AET})\right]$ & 6b & $P 2_{1} / c$ & 2.072 & 143 & Brown & 1,1 & $1,1,1$ & $1,1,3$ \\
\hline$\left[\mathrm{Cu}_{4}\left(\mathrm{~N}_{3}\right)_{8}(2,2-\mathrm{dte})\right]$ & 10 & $P \overline{1}$ & 2.200 & 143 & Brown & 1,1 & $1,1,1$ & $1,1,3$ \\
\hline$\left[\mathrm{Cu}_{4}\left(\mathrm{~N}_{3}\right)_{8}(2,2-\mathrm{dtp})\right]$ & 12 & $C 2 / c$ & 2.136 & 123 & Brown & 1,1 & $1,1,1$ & $1,1,3$ \\
\hline
\end{tabular}

${ }^{a}$ Crystallographic density at cell measurement temperature. ${ }^{b}$ Cell measurement temperature. ${ }^{c}$ Colour of the single crystal used for X-ray diffraction experiments. ${ }^{d}$ Different types of bridging observed for the azido ligands in the respective crystal structure.

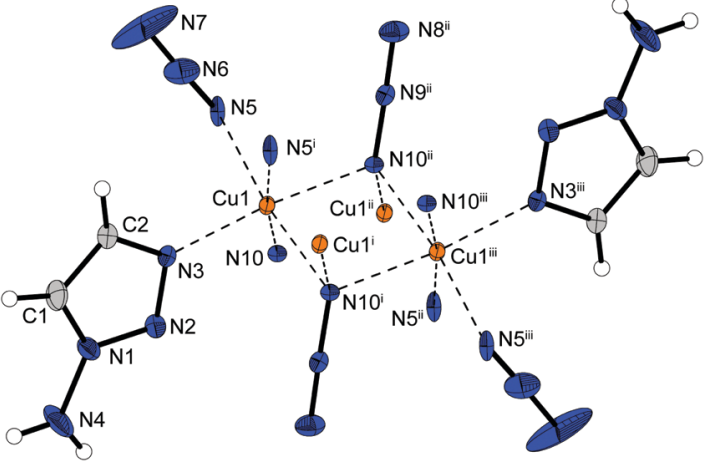

Fig. 2 Copper(II) coordination environment of $\left[\mathrm{Cu}\left(\mathrm{N}_{3}\right)_{2}(1-\mathrm{ATRI})\right]$ (1). Selected bond lengths (Å): Cu1-N3 1.982(3), Cu1-N5 2.037(3), Cu1N10 2.580(4); selected bond angles ( ${ }^{\circ}$ : N3-Cu1-N5 94.16(12), N3-Cu1N10 95.47(12), N3-Cu1-N10ii 173.72(13), N5-Cu1-N10 83.55(12). Symmetry codes: (i) $-1+x, y, z$; (ii) $1-x,-y, 1-z$.

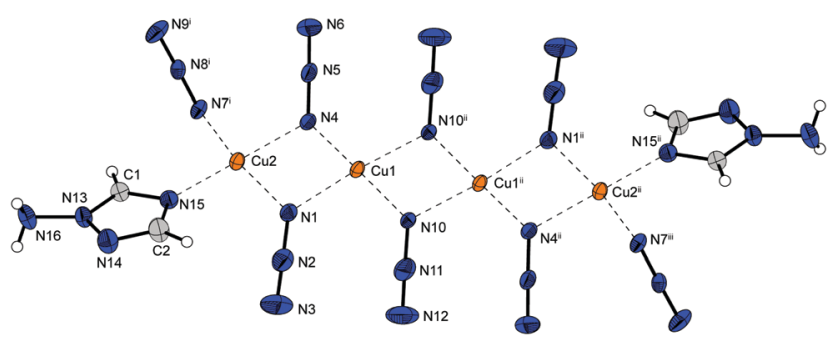

Fig. 3 Copper(II) coordination environment of $\left[\mathrm{Cu}_{2}\left(\mathrm{~N}_{3}\right)_{4}(1-\mathrm{A}-1,2,4-\mathrm{TRI})_{2}\right]$ (2). Selected bond lengths (Å): Cu1-N1 2.005(3), Cu1-N4 2.001(3), Cu1N7 2.409(3), Cu1-N4 2.878(3), Cu1-N10ii 2.021(4), Cu1-N10 2.016(3), Cu2-N9 2.593(3), Cu2-N15 1.980(4), Cu2-N10 2.658(3); selected bond angles ( ${ }^{\circ}$ : N7-Cu1-N4 $173.08(12), \mathrm{Cu} 1-\mathrm{N} 4-\mathrm{Cu} 2$ 101.37(14), N9 ${ }^{\mathrm{iv}}-\mathrm{Cu} 2-$ N7i 96.27(11), N9 ${ }^{i v}-C u 2-N 15$ 85.61(13), N7-Cu1-N1 101.70(13). Symmetry codes: (i) $-1+x, y, z$; (ii) $2-x, 1-y, 1-z$; (iii) $3-x, 1-y, 1-z$; (iv) $2-x$, $-y, 1-z ;$ (v) $1-x, 1-y, 1-z$.

around the central metal of the herein presented complexes. The coordination sphere around $\mathrm{Cu} 1$ is completed by two 1,1linking azido anions in axial positions causing a typical Jahn-

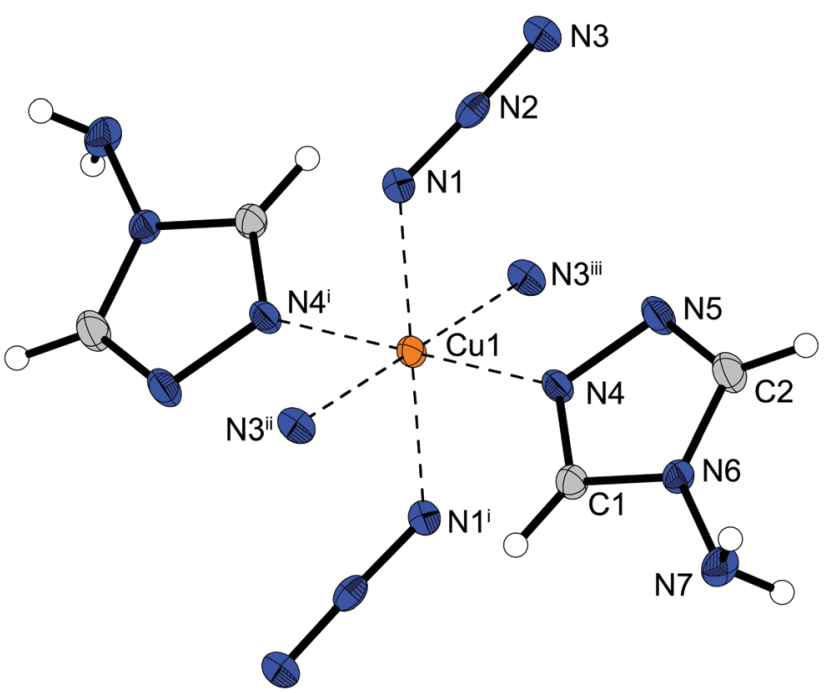

Fig. 4 Copper(॥) coordination environment of $\left[\mathrm{Cu}\left(\mathrm{N}_{3}\right)_{2}(4-\mathrm{ATRI})_{2}\right]$ (3). Selected bond lengths (Å): Cu1-N1 2.006(2), Cu1-N4 2.005(2), Cu1-N3 $3^{\mathrm{ii}}$ 2.523(2); selected bond angles ( ${ }^{\circ}$ : $\mathrm{N} 1-\mathrm{Cu} 1-\mathrm{N} 492.30(9), \mathrm{N} 1-\mathrm{Cu} 1-\mathrm{N} 3^{\mathrm{ii}}$ 88.78(8), N3 $3^{\mathrm{ii}}-\mathrm{Cu} 1-\mathrm{N} 4$ 85.61(8). Symmetry codes: (i) $-x,-y,-z$; (ii) $-1+x$, $y, z$; (iii) $1-x,-y,-z$.

Teller distortion (Cu1-N13 2.355(4) Å). The azido ligands around $\mathrm{Cu} 2$ show two additional coordination modes, a rather unconventional monodentate binding (Chart 2: 1) and a 1,3bridging similar to 3 leading to the formation of $1 \mathrm{D}$ polymeric chains. Interestingly, latter coordination mode can only be observed in these two compounds, which are the only green coloured ones. Whereas in 3 the JT-distortion of the 1,3-azido ligands is close to $2.5 \AA$, it is astonishingly long in complex 4 $\left(\mathrm{Cu} 2-\mathrm{N} 21^{\mathrm{ii}}=2.825(6) \AA\right)$. The crystal structure shows strong disordering effects in the monodentate azido ligand as well as in the crystal water molecule.

Complex compound $\mathbf{5 b}$ crystallizes in the form of red platelets in the monoclinic space group $P 2_{1} / c$. It possesses four formula units per unit cell and a calculated density of $2.065 \mathrm{~g} \mathrm{~cm}^{-3}$ at 173 K. Every copper(II) cation is octahedral coordinated by one bistriazole (BTRI) molecule and five azide anions (Fig. 7). 

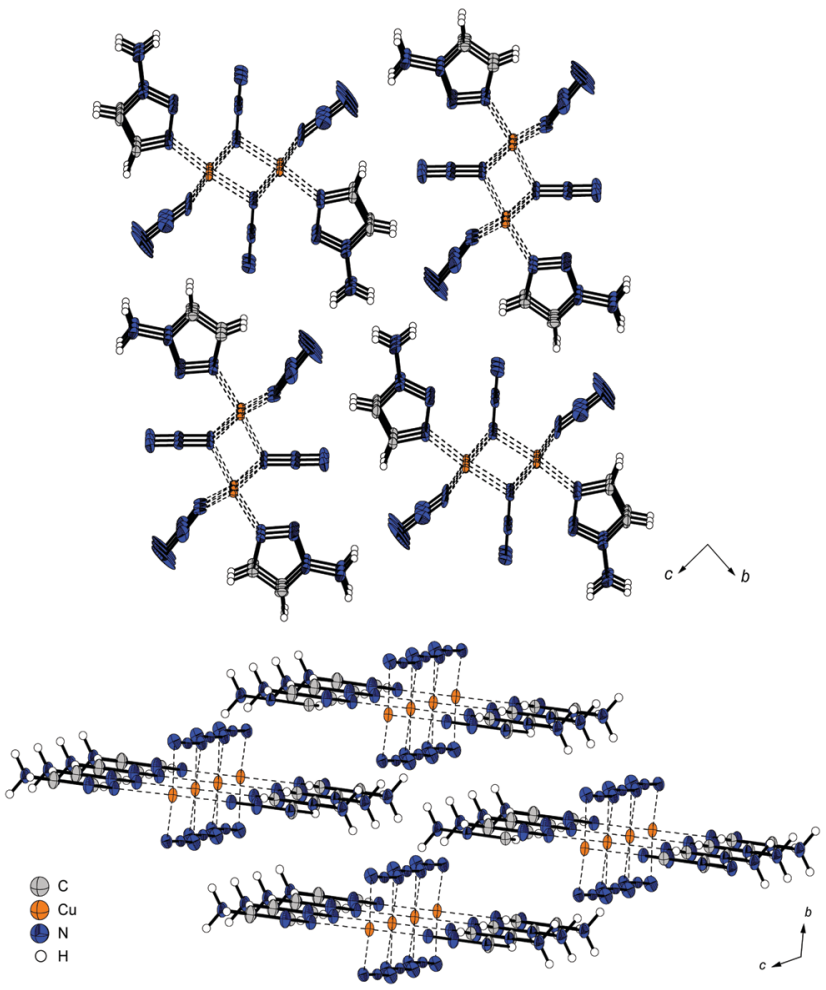

Fig. 5 1-D polymeric chains of 1 (top) and $\mathbf{3}$ (bottom) along the a axis.

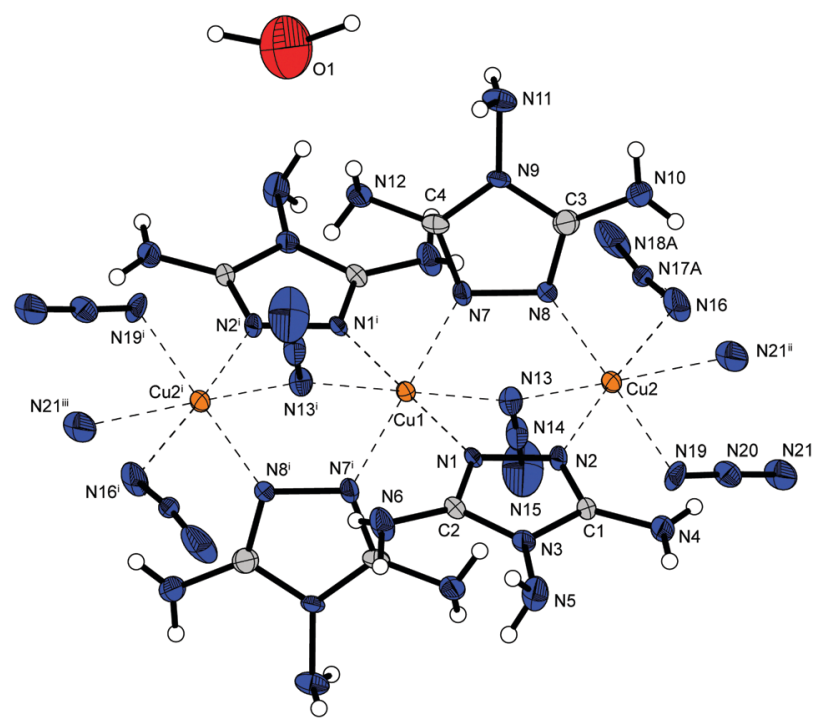

Fig. 6 Coordination environment of trinuclear unit of $\left[\mathrm{Cu}_{3}\left(\mathrm{~N}_{3}\right)_{6}(\mathrm{TATRI})_{4}\right]$. $0.5 \mathrm{H}_{2} \mathrm{O}$ (4). Selected bond lengths (Å): Cu1-N13 2.355(4), Cu1N1 2.033(4), Cu1-N7 1.993(5), Cu2-N2 1.991(5), Cu2-N8 2.015(4), Cu2N13 2.264(5), Cu2-N16 1.978(6), Cu2-N19 2.005(4); selected bond angles $\left({ }^{\circ}\right)$ : N1-Cu1-N7 89.38(19), N7-Cu1-N7 180, N7-Cu1-N13 84.99(18), N2-Cu2-N8 89.18(18), N2-Cu2-N16 171.1(3), N2-Cu2-N21 ${ }^{\mathrm{ii}}$ 88.78(18), N8-Cu2-N16 90.7(2). Symmetry codes: (i) $2-x, 1-y,-z$; (ii) $2-x_{1} 2-y, 1-z,($ iii) $x,-1+y,-1+z$.

The polyhedrons are linked over the azide anions in two different ways forming two dimensional layers. (Chart 2: 1,1,3; 1,1).

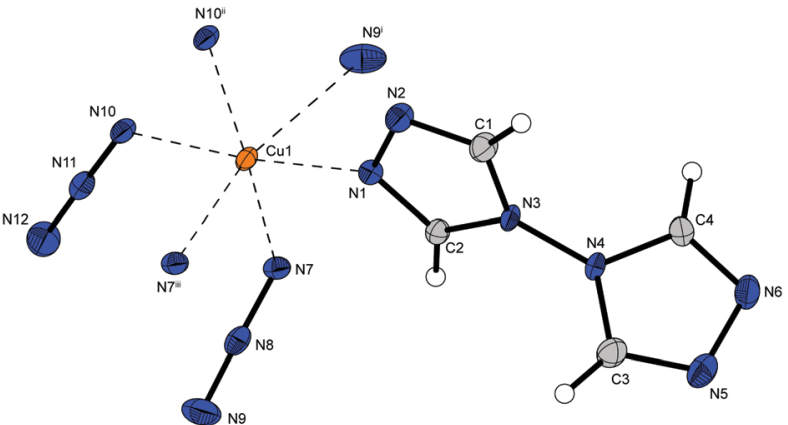

Fig. 7 Coordination environment of $\left[\mathrm{Cu}\left(\mathrm{N}_{3}\right)_{2}(\mathrm{BT} z)\right]$ (5b). Selected bond lengths (Å): Cu1-N1 1.9858 (16), Cu1-N7 2.0016(16), Cu1-N10 1.9968(16), Cu1-N9i 2.7764(19), Cu1-N77ii 2.5212(19), Cu1-N10ii 2.0083(17); selected bond angles ( ${ }^{\circ}$ ): N1-Cu1-N9i 79.83(7), N1-Cu1-N10ii 97.42(7), N7-Cu1N9i 84.33(7), N7-Cu1-N7 iii 92.55(6). Symmetry codes: (i) $-x_{1}-0.5+y$, $0.5-z$; (ii) $-x, 0.5+y, 0.5-z$; (iii) $-x, 1-y,-z$.

Azide complex $\left[\mathrm{Cu}\left(\mathrm{N}_{3}\right)_{2}(\mathrm{AET})\right]$ (6a) crystallizes as brown plates in the monoclinic space group $I 2 / a$ with eight formula units per unit cell and a calculated density of $2.003 \mathrm{~g} \mathrm{~cm}^{-3}$ at $143 \mathrm{~K}$. The octahedral coordination sphere around the copper(II) centre of $\mathbf{6 a}$ is made up of one molecule of AET and five azide anions and is Jahn-Teller distorted along N11 ${ }^{\mathrm{i}}-\mathrm{Cu} 1-$ N13 ${ }^{\text {iii }}$ (Fig. 8). The metal centres form double strands, that extend through the structure, bridged by azide anions (Chart 2: 1,1). The different chains are linked by a second species of azido ligands (Chart 2: 1,1,3) leading to the formation of a 2D-polymeric network.

The by-product $\left[\mathrm{Cu}_{2}\left(\mathrm{~N}_{3}\right)_{4}(\mathrm{AET})\right](6 \mathrm{~b})$ crystallizes as brown rods in the monoclinic space group $P 2_{1} / c$ with four formula units per unit cell and a calculated density of $2.072 \mathrm{~g} \mathrm{~cm}^{-3}$ at 143 K. Similar to 6a, 1,1 and 1,1,3 bridging azido ligands are leading to the formation of 2D-polymeric networks. But, as already observed in compound 2 , the existence of azide anions in an additional 1,1,1 coordination mode is building up strands consisting of four copper ions (Fig. 9). The centrosymmetric unit is completed by two AET ligands, that coordinate to the

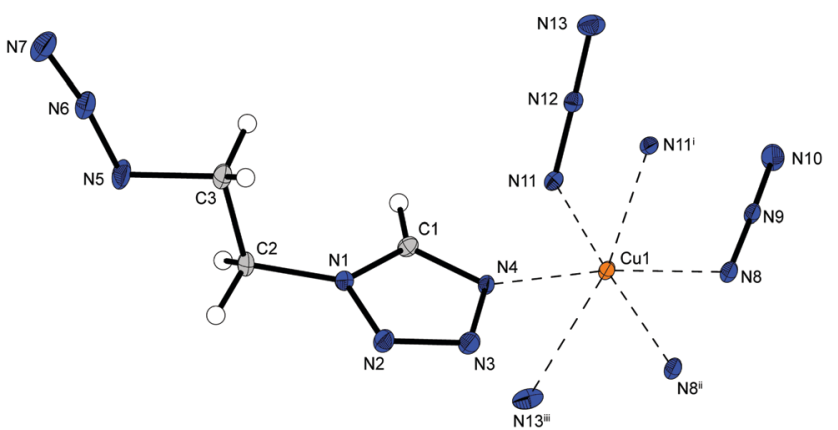

Fig. 8 Coordination environment of $\left[\mathrm{Cu}\left(\mathrm{N}_{3}\right)_{2}(\mathrm{AET})\right]$ (6a). Selected bond lengths (Å): Cu1-N4 1.985(2), Cu1-N8 1.995(2), Cu1-N8ii 2.011(2), Cu1N11 2.001(2), Cu1-N11' 2.5095(19), Cu1-N13 $3^{i i i}$ 2.736(3). Selected bond angles ( ${ }^{\circ}$ ): N4-Cu1-N8 173.22(8), N4-Cu1-N8 ii 97.39(8), N4-Cu1-N11 90.70(8), N4-Cu1-N11' 90.70(7), N4-Cu1-N13 iii 79.21(8), N8 ${ }^{\mathrm{ii}}-\mathrm{Cu} 1-\mathrm{N} 11$ 169.61(8), N11'-Cu1-N13 $3^{\mathrm{iii}} 169.29$ (7). Symmetry codes: (i) $1-x_{1}-0.5+y$, $0.5-z$; (ii) $1.5-x, 0.5-y, 0.5-z$; (iii) $1-x, 0.5+y, 0.5-z$. 


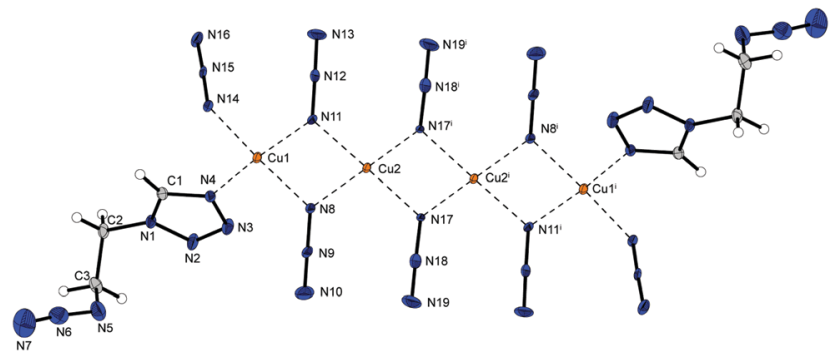

Fig. 9 Molecular unit of by-product $\left[\mathrm{Cu}_{2}\left(\mathrm{~N}_{3}\right)_{4}(\mathrm{AET})\right](6 \mathbf{6})$. Selected bond lengths (Å): Cu1-N4 1.984(3), Cu1-N8 2.001(3), Cu1-N11 2.009(3), Cu1N14 1.978(3), Cu2-N8 1.994(3), Cu2-N11 1.996(3), Cu2-N17 1.998(3). Selected bond angles $\left({ }^{\circ}\right)$ : N4-Cu1-N8 96.38(12), N4-Cu1-N11 170.51(11), N4-Cu1-N14 92.36(12), N8-Cu1-N11 78.91(11), N8-Cu2N11 79.39(11), N8-Cu2-N17 100.72(11). Symmetry code: (i) $2-x,-y,-z$.

outer copper centres on opposite sites, whereas the inner two cations are only bounded to azido ligands. All metal centres are Jahn-Teller distorted along the axis vertical to the plane shown in Fig. 9, bond lengths are partly notably longer than in other JT-distorted complexes, from $2.5 \AA$ to even exceeding $2.7 \AA$ A.

In both copper(II) azide complexes of AET the 2D-polymeric networks are formed by the 1,1,3 coordinating azido ligands bridging between strands of copper ions (Fig. 10). While the existence of solely 1,1 binding azido ligands are building up double strands (6a) of cations, the combination of 1,1 and 1,1,1 anions is leading to quadruple strands $(\mathbf{6 b})$.

Compound 7 , based on the ligand 1-azidopropyl- $5 \mathrm{H}^{-}$ tetrazole, crystallizes as brown platelets in the monoclinic space group $P 2_{1} / c$ with four formula units per unit cell and the lowest of all calculated densities $\left(1.897 \mathrm{~g} \mathrm{~cm}^{-3}\right.$ @ $\left.109 \mathrm{~K}\right)$. The octahedral coordination sphere around the copper(II) centre of compound 7 shows an almost identical built up like
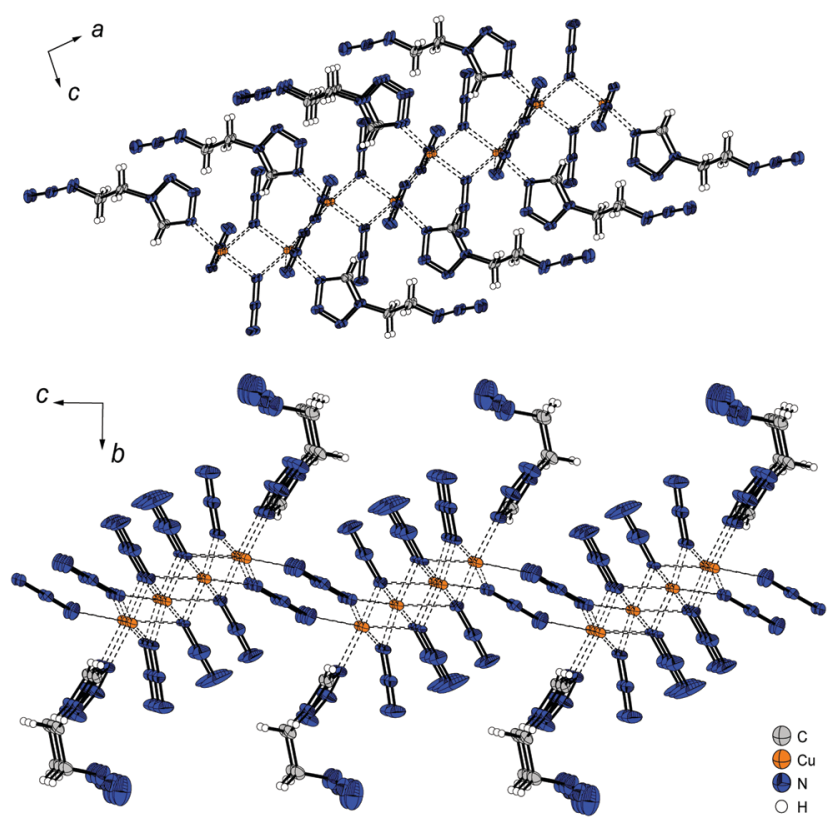

Fig. 10 Polymeric layers of $\mathbf{6 a}$ (top) along the $b$ axis and $\mathbf{6 b}$ (bottom) along the a axis.

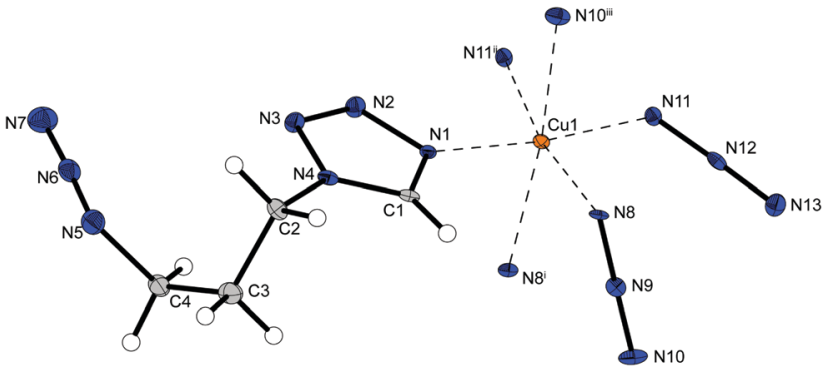

Fig. 11 Coordination environment of $\left[\mathrm{Cu}\left(\mathrm{N}_{3}\right)_{2}(\mathrm{APT})\right]$ (7). Selected bond lengths (Å): Cu1-N1 1.984(3), Cu1-N8 2.005(3), Cu1-N8i 2.519(3), Cu1N10iii 2.702(4), Cu1-N11 2.006(3). Selected bond angles ( ${ }^{\circ}$ : N1-Cu1-N8 90.88(14), N1-Cu1-N11 173.33(14), N8-Cu1-N10iii 84.06(11), N8ii-Cu1N11 169.61(8), N8-Cu1-N11ii 169.86(14), N11-Cu1-N11ii 77.54(13). Symmetry codes: (i) $1-x,-0.5+y, 1.5-z$; (ii) $1-x, 1-y, 1-z$; (iii) $1-x, 0.5+y, 1.5-z$

compound 6a and is made up of one molecule of APT and five azide anions with the same coordination modes as in $\mathbf{6 a}$ (Chart 2: 1,1; 1,1,3) leading again to the formation of a 2Dpolymeric network (Fig. 11).

The unique trinuclear complex $\mathbf{8}$ crystallizes as red platelets in the triclinic space group $P \overline{1}$ with one formula unit per unit cell and a calculated density of $2.103 \mathrm{~g} \mathrm{~cm}^{-3}$ at $293 \mathrm{~K}$. The structure of $\mathbf{8}$ shows exceptional characteristics in many respects. It is the only compound which shows a bridging of single tetrazole rings between two different copper(II) atoms leading to the blocking of two coordination sites of $\mathrm{Cu} 1$. Furthermore, it prevents the linking of the N12-N13-N14 azide anion (comparable to 4) causing a mono-bonded anion with the shortest $\mathrm{Cu}-\mathrm{N}(\mathrm{Cu} 2-\mathrm{N} 12$ 1.9558(19) $\AA$ ) bond of all observed

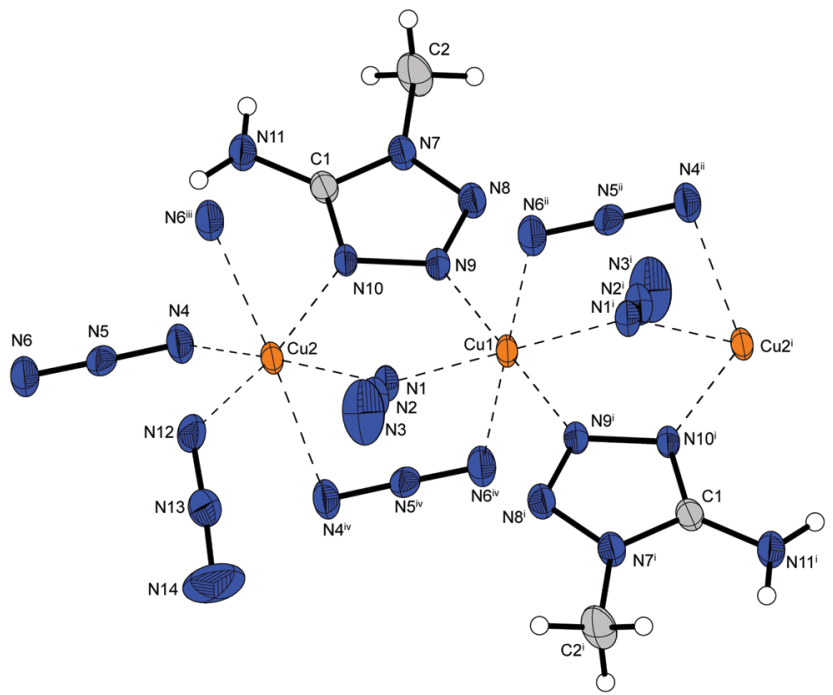

Fig. 12 Extended molecular unit of $\left[\mathrm{Cu}_{3}\left(\mathrm{~N}_{3}\right)_{6}(1-\mathrm{MAT})\right](8)$. Selected bond lengths (Å): Cu1-N1 1.9903(18), Cu1-N6ii 2.5836(18), Cu2-N1 2.0205(17) Cu2-N4 1.9922(17), Cu2-N4 ${ }^{\mathrm{iv}} 2.721(2)$. Selected bond angles $\left({ }^{\circ}\right)$ : Cu1-N1Cu2 120.65(8), N1-Cu1-N9 85.40(7), N1-Cu1-N1 180.00, N6iv -Cu1-N9 84.47(7), N1-Cu2-N4 164.45(8), N4-Cu2-N4iv 82.23(7), N4 ${ }^{\text {iv }}-\mathrm{Cu} 2-\mathrm{N} 10$ 97.75(7). Symmetry codes: (i) $-x,-y,-z$; (ii) $x,-1+y, z$; (iii) $-1-x, 1-y$, $-z$; (iv) $-x, 1-y,-z$. 


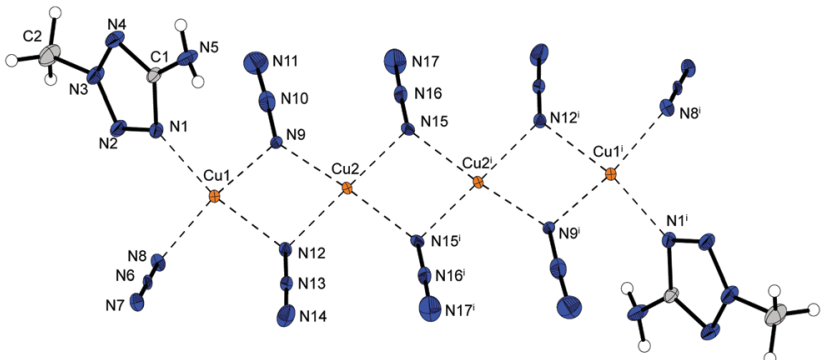

Fig. 13 Copper(II) coordination environment of $\left[\mathrm{Cu}_{4}\left(\mathrm{~N}_{3}\right)_{8}(2-\mathrm{MAT})_{2}\right]$ (9). Selected bond lengths (Å): Cu1-N1 1.998(3), Cu1-N8 1.983(3), Cu1N9 1.974(3), Cu1-N12 2.032(3), Cu2-N9 1.964(3), Cu2-N12 2.024(3), Cu2-N15 2.018(3); selected bond angles ( $\left.{ }^{\circ}\right)$ : N1-Cu1-N8 96.98(12), N1-Cu1-N12 168.34(12), N1-Cu1-N9 90.49(12), N8-Cu1-N9 165.71(12), N9-Cu1-N12 78.84(12), N12-Cu2-N15 175.19(11), N9-Cu2-N12 79.28(12), N9-Cu2-N15 100.17(12), Cu1-N9-Cu2 102.55(14), Cu1-N12Cu2 98.47(12). Symmetry code: (i) $-x, 1-y,-z$.

structures. The anions show three different coordination modes in the complex. While the 1,1-linking was already observed in many structures it shows another unique quadruple 1,1,3,3 (Chart 2) bridging of azide moieties between four different cations (Fig. 12).

The copper(II) azide complex 9 shows a high density $\left(2.188 \mathrm{~g} \mathrm{~cm}^{-3}\right.$ at $173 \mathrm{~K}$ ) and crystallizes in the form of red rods in the monoclinic space group $P 2_{1} / n$ with four formula units per unit cell. Two asymmetric unit cells build up the molecular unit (Fig. 13). The asymmetric unit of the compound contains two different copper(II) centres - both of them are coordinated octahedrally. Similar to $\mathbf{2}$ and $\mathbf{6 b}$ the combination of three different bridging modes of the anions (Chart 2: 1,1; 1,1,1; $1,1,3$ ) are leading the formation of polymeric $2 \mathrm{D}$-structures with $\mathrm{Cu} 1$ coordinated by five azido anions and one 2-MAT ligand as well as $\mathrm{Cu} 2$ solely surrounded by six azido ligands.

Complex compound $\mathbf{1 0}$ crystallizes in the triclinic space group $P \overline{1}$ in from of brown needles, with a very high calculated density ( $2.200 \mathrm{~g} \mathrm{~cm}^{-3}$ at $143 \mathrm{~K}$ ) and two formula units per unit cell.

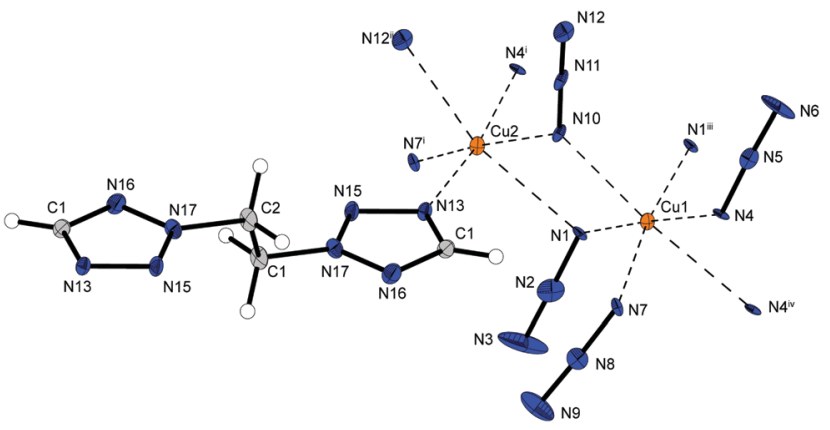

Fig. 14 Coordination environment of $\left[\mathrm{Cu}_{4}\left(\mathrm{~N}_{3}\right)_{8}(2,2-\mathrm{dte})\right]$ (10). Selected bond lengths (Å): Cu1-N1 1.991(5), Cu1-N4 ${ }^{\mathrm{iv}} 2.703(5), \mathrm{Cu} 1-\mathrm{N} 10$ 2.392(6), Cu2-N1 2.671(5), Cu2-N10 1.970(5), Cu2-N12ii 2.530(6), Cu2N13 1.988(6); selected bond angles ( ${ }^{\circ}$ : N1-Cu1-N10 84.5(2), N4-Cu1N7 79.5(2), N4-Cu1-N4iv 80.45(19), N1-Cu2-N10 77.7(2), N10-Cu2-N12ii 94.9(2), N10-Cu2-N13 91.5(2), Cu1-N1-Cu2 93.7(2), Cu1-N10-Cu2 103.4(3). Symmetry codes: (i) $-1+x, y, z$; (ii) $1+x, y, z$; (iii) $-x,-y, 1-z$; (iv) $1-x,-y, 1-z$.

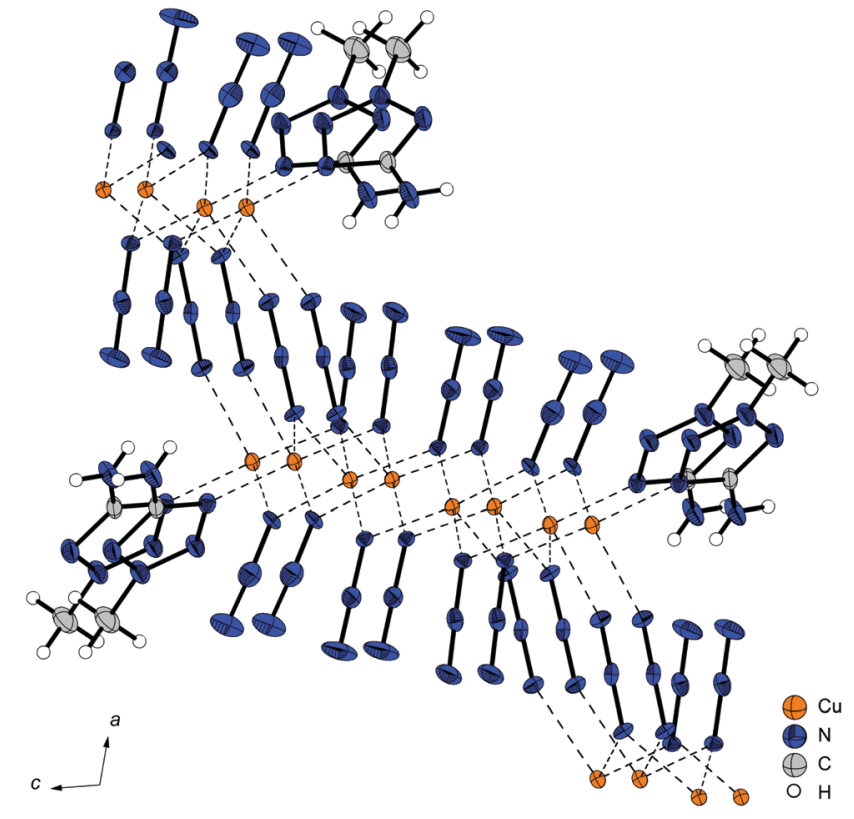

Fig. 15 Polymeric structures of 9 along the $b$ axis.

The molecular unit cell is built up out of four copper centres, one ligand molecule, and eight azide anions (Fig. 14). Again, the presence of 1,1, 1,1,1, and 1,1,3 coordinating azido ligands is leading to quadruple strands of copper ions bridged to polymeric networks. In contrast to $\mathbf{2}, \mathbf{6 b}$, and $\mathbf{9}$, the use of a ditetrazole instead of a monotetrazole ligand is causing a further linkage of the polymeric layers leading to $3 \mathrm{D}$ structures.

Comparable to $\mathbf{2}$ and $\mathbf{6 b}$, in $\mathbf{9}$ and $\mathbf{1 0}$ quadruple strands of copper(II) ions are formed by 1,1,1-linking azido anions and further connected by 1,1,3-bridging ligands to polymeric networks (Fig. 15 and 16). While both ligands 2-MAT and 2,2dte are only blocking one of the coordination sites of every second central metal, the later one is also combining the layers to 3D-networks, by binding to two copper(II) cations of different levels.

$\left[\mathrm{Cu}_{4}\left(\mathrm{~N}_{3}\right)_{8}(2,2\right.$-dtp) $]$ (12) crystallizes in the form of brown needles in the monoclinic space group $C 2 / c$ with four formula units per unit cell and a calculated density of $2.136 \mathrm{~g} \mathrm{~cm}^{-3}$ at $123 \mathrm{~K}$. Compound $\mathbf{1 2}$ shows almost the same consistency as $\mathbf{1 0}$

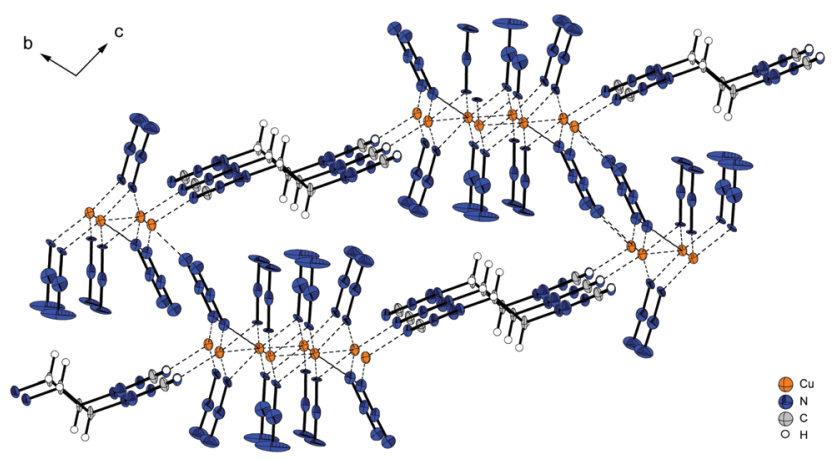

Fig. 16 Polymeric structures of $\mathbf{1 0}$ along the a axis. 


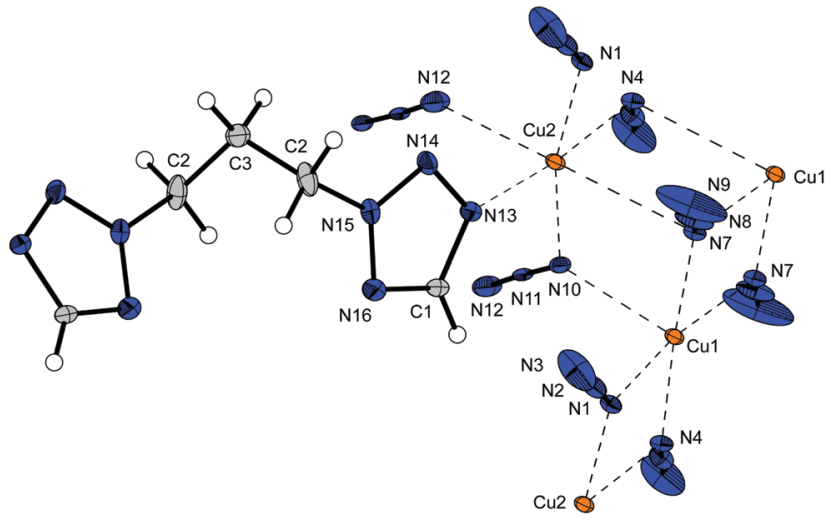

Fig. 17 Molecular unit of $\left[\mathrm{Cu}_{4}\left(\mathrm{~N}_{3}\right)_{8}(2,2-\mathrm{dtp})\right]$ (12). Selected bond lengths (Å): Cu1-N1 1.995(3), Cu1-N4 1.995(3), Cu1-N7 2.003(3), Cu1N10 2.374(3), Cu2-N7 2.683(3), Cu2-N10 1.978(3), Cu2-N13 1.986(3): selected bond angles $\left({ }^{\circ}\right)$ : N1-Cu1-N4 78.78(12), N1-Cu1-N7 101.45(12), N1-Cu1-N10 98.06(11), N4-Cu1-N7 176.02(12), N7-Cu2-N10 78.39(11), N7-Cu2-N13 100.76(10), Cu1-N7-Cu2 92.17(11), Cu1-N10-Cu2 102.74(12). Symmetry codes: (i) $0.5-x, 0.5-y,-z$; (ii) $x, 1+y, z$; (iii) $-x, 1-y,-z$; (iv) $x,-1+y, z$; (v) $-x, y, 0.5-z$.

with a molecular unit built up of four copper(II) cations (Fig. 17), eight azide moieties, and one ditetrazole ligand. Whereas the outer two copper(II) atoms (Cu2) are coordinated to one tetrazole ring and five azide ligands, the inner two (Cu1) are only coordinating to anions.

The three different bridging modes (Chart 2: 1,1; 1,1,1; 1,1,3) of the anions along the $a$ and $b$ axis are leading to the formation of polymeric 2D-layers, only containing copper(II) and azide ions. The additionally linking of two copper(II) atoms by the ditetrazole ligand along the $c$ axis (Fig. 18) is finalizing the development of a 3D-polymer with unique physical properties. Due to the strong steric hindrance, there is a large deviation of the ideal octahedral coordination sphere.

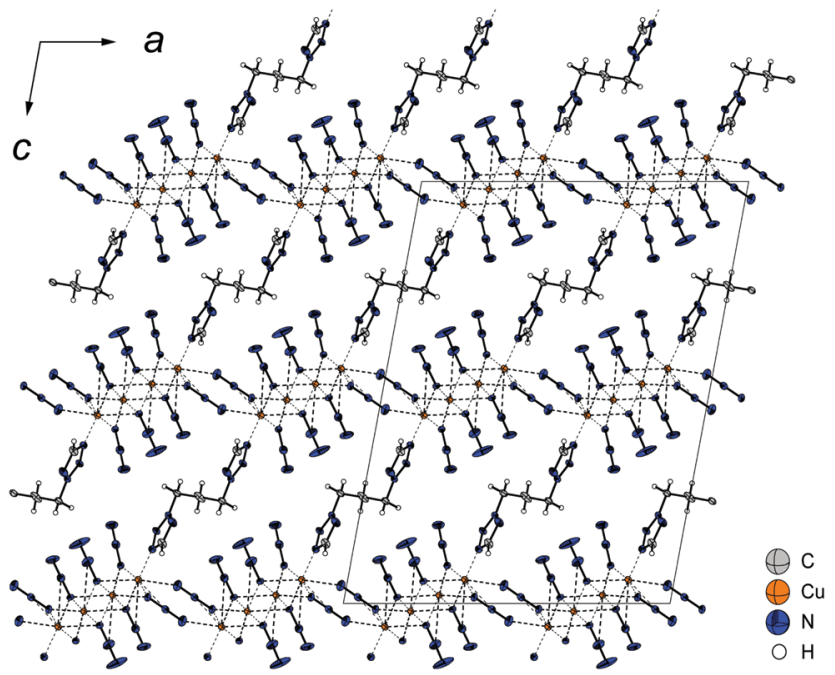

Fig. 18 Polymeric 3D-structure of 12 along the $b$ axis. The ligand is bridging quadruple strands of copper(II) along the $c$ axis with a small shift along the $a$ axis.

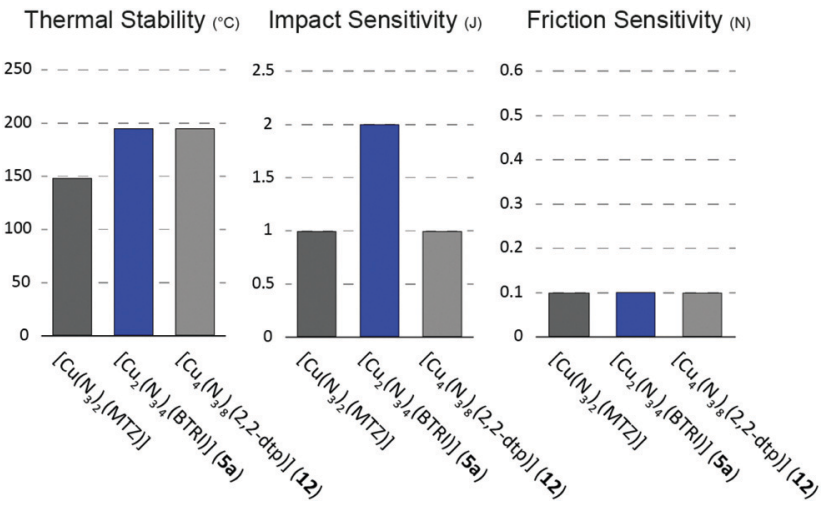

Fig. 19 Comparison of $\left[\mathrm{Cu}\left(\mathrm{N}_{3}\right)_{2}(\mathrm{MTZ})\right]$ with compound $5 \mathrm{a}$ and 12

\section{Thermal stability and sensitivity measurements}

The complexes' thermal stability was investigated using differential thermal analysis (DTA) at a heating rate of $5{ }^{\circ} \mathrm{C} \mathrm{min}^{-1}$. The DTA curves, in the range from $50-400{ }^{\circ} \mathrm{C}$ can be found in the (Fig. S10-S12, ESI $\$$ ). Measurements of the compounds 2, $\mathbf{5 b}, \mathbf{6 b}$, and $\mathbf{8}$ were waived as no elemental analysis pure samples could be obtained of these complexes.

Overall, the exothermic events of only four compounds are below $150{ }^{\circ} \mathrm{C}(\mathbf{1}, \mathbf{6 a}, 7, \mathbf{1 1})$. The majority of the compounds is exceeding $150{ }^{\circ} \mathrm{C}(\mathbf{3}, \mathbf{4}, \mathbf{9}, \mathbf{1 3})$, with three ECCs even possessing very good thermal stabilities of at least $190{ }^{\circ} \mathrm{C}(\mathbf{5 a}, \mathbf{1 0}, \mathbf{1 2})$. Those are significantly more stable than previously published $\left[\mathrm{Cu}\left(\mathrm{N}_{3}\right)_{2}(1-\text { methyl-5H-tetrazole })^{29}\right.$ (Fig. 19). Endothermic events, which generally indicate a phase transition, melting, or a loss of ligand or hydrate water were observed only for $\left[\mathrm{Cu}\left(\mathrm{N}_{3}\right)_{2}(\mathrm{APT})\right]$ (7). Here, thermogravimetric measurements (TG) showed that upon heating, the ligand evaporates from the complex, indicating, that the ECC is not stable.

The decomposition points are in every case related to the complexes' structure. In case of the ditetrazoles based ECCs 10-13, the high thermal stability is caused by the 3D polymeric structure formed by azido and tetrazole ligands. However, the complexes based on ligands like i-dtp and 1,2-dtp are known to possess lower thermal stabilities than the ECCs based on the respective 2,2substituted isomers. ${ }^{43,56}$ The assumption that $\left[\mathrm{Cu}_{2}\left(\mathrm{~N}_{3}\right)_{4}(\mathrm{BTRI})\right]$ (5a) exhibits bridging BTRI ligands is supported by the thermal stability of the compound $\left(T_{\text {exo }}=195{ }^{\circ} \mathrm{C}\right)$.

Consequently, one would assume that the remaining complexes, which exhibit a 2D polymeric network, possess higher thermal stabilities than those which form only onedimensional chains. However, the two complexes $6 \mathbf{a}\left(T_{\text {exo }}=\right.$ $\left.131{ }^{\circ} \mathrm{C}\right)$ and $7\left(T_{\text {exo }}=132{ }^{\circ} \mathrm{C}\right)$ unfortunately do not follow this trend. In this case, accelerated decomposition catalysed by the copper cations is probably the reason for the earlier exothermic events. Thus, similar effects in copper complexes based on these ligands have already been observed in previous works of our group. ${ }^{39,40}$ The third complex having a 2D structure, $\left[\mathrm{Cu}_{4}\left(\mathrm{~N}_{3}\right)_{8}(2-\mathrm{MAT})_{2}\right](\mathbf{9})$, is showing a sufficient thermal stability of $161{ }^{\circ} \mathrm{C}$, however measurements regarding compound 3 and 4, only forming $1 \mathrm{D}$ polymeric chains, gave exothermic events at the same or even higher temperatures 
Table 2 Overview of the compounds' thermal stability ${ }^{a}$ and sensitivities toward various external stimuli compared to lead azide ${ }^{b}$

\begin{tabular}{|c|c|c|c|c|c|c|}
\hline Compound & & $\begin{array}{l}T_{\text {endo. }}{ }^{c} \\
\left({ }^{\circ} \mathrm{C}\right)\end{array}$ & $\begin{array}{l}T_{\text {exo. }}{ }^{d} \\
\left({ }^{\circ} \mathrm{C}\right)\end{array}$ & $\begin{array}{l}\mathrm{IS}^{e} \\
(\mathrm{~J})\end{array}$ & $\mathrm{FS}^{f}(\mathrm{~N})$ & $\begin{array}{l}\mathrm{ESD}^{g} \\
(\mathrm{~mJ})\end{array}$ \\
\hline$\left[\mathrm{Cu}\left(\mathrm{N}_{3}\right)_{2}(1-\mathrm{ATRI})\right]$ & 1 & - & 123 & 3 & $<5$ & 5 \\
\hline$\left[\mathrm{Cu}\left(\mathrm{N}_{3}\right)_{2}(4-\mathrm{ATRI})_{2}\right]$ & 3 & - & 161 & 10 & $>360$ & 300 \\
\hline$\left[\mathrm{Cu}_{3}\left(\mathrm{~N}_{3}\right)_{6}(\mathrm{TATRI})\right] \cdot 0.5 \mathrm{H}_{2} \mathrm{O}$ & 4 & - & 170 & 15 & $>360$ & 250 \\
\hline$\left[\mathrm{Cu}_{2}\left(\mathrm{~N}_{3}\right)_{4}(\mathrm{BTRI})\right]$ & $5 \mathbf{a}$ & - & 195 & 2 & $\leq 0.1$ & 5 \\
\hline$\left[\mathrm{Cu}\left(\mathrm{N}_{3}\right)_{2}(\mathrm{AET})\right]$ & $6 \mathbf{a}$ & - & 131 & $<1$ & $\leq 0.1$ & 1.1 \\
\hline$\left[\mathrm{Cu}\left(\mathrm{N}_{3}\right)_{2}(\mathrm{APT})\right]$ & 7 & 54 & 132 & $<1$ & 4.5 & 2.5 \\
\hline$\left[\mathrm{Cu}_{4}\left(\mathrm{~N}_{3}\right)_{8}(2-\mathrm{MAT})_{2}\right]$ & 9 & - & 161 & $<1$ & $<5$ & 13 \\
\hline$\left[\mathrm{Cu}_{4}\left(\mathrm{~N}_{3}\right)_{8}(2,2\right.$-dte $\left.)\right]$ & 10 & - & 190 & $<1$ & $<5$ & 5 \\
\hline$\left[\mathrm{Cu}_{2}\left(\mathrm{~N}_{3}\right)_{4}(1,2-\mathrm{dtp})\right]$ & 11 & - & 146 & 3 & $<5$ & 18 \\
\hline$\left[\mathrm{Cu}_{4}\left(\mathrm{~N}_{3}\right)_{8}(2,2-\mathrm{dtp})\right]$ & 12 & - & 195 & 1 & $\leq 0.1$ & 5 \\
\hline$\left[\mathrm{Cu}_{2}\left(\mathrm{~N}_{3}\right)_{4}(\mathrm{i}-\mathrm{dtp})\right]$ & 13 & - & 165 & 2 & $<5$ & 5 \\
\hline $\mathrm{Pb}\left(\mathrm{N}_{3}\right)_{2}(\mathrm{RD}-1333)^{59,60}$ & - & - & $320-350$ & 4 & $\leq 0.1$ & $0.007-5$ \\
\hline \multicolumn{7}{|c|}{$\begin{array}{l}{ }^{a} \text { Onset temperatures at a heating rate of } 5{ }^{\circ} \mathrm{C} \mathrm{min}^{-1} \cdot{ }^{b} \text { Determined by } 1 \\
\text { of } 6 \text { method. }{ }^{57}{ }^{c} \text { Endothermic peak, which indicates a loss of ligands. } \\
{ }^{d} \text { Exothermic peak, which indicates decomposition. }{ }^{e} \text { Impact sensitivity } \\
\text { (BAM drop hammer test). }{ }^{61,62 f} \text { Friction sensitivity (BAM friction } \\
\text { tester). }{ }^{63,64} \text { g } \\
\text { Electrostatic discharge sensitivity (OZM XSpark10). }{ }^{65}\end{array}$} \\
\hline
\end{tabular}

(3: $T_{\text {exo }}=161{ }^{\circ} \mathrm{C}$; 4: $T_{\text {exo }}=170{ }^{\circ} \mathrm{C}$ ). Accordingly, the hydrogen bonding specifically formed by the amino groups of the ligands in 3 and $\mathbf{4}$ are believed to counterbalance the effects of a 2D polymer on the thermal stabilities of a complex. The rather poor thermal stability of $\left[\mathrm{Cu}\left(\mathrm{N}_{3}\right)_{2}(1-\mathrm{ATRI})\right]$ (1) is probably due to the double strand formed in the crystal structure by the azido ligands. Conclusively, it can be stated, that especially the use of bridging BTRI or ditetrazoles ligands leads to ECCs possessing a better thermal stability than those presented in our previous work. ${ }^{29}$

Since sensitivity data are some of the most important safety parameters in the field of energetic materials, especially when it comes to primary explosives, special emphasis was placed on it. For this purpose, sensitivity measurements with regard to impact (IS) and friction sensitivity (FS) were carried out according to BAM (Bundesamt für Materialforschung und -prüfung) standard methods. ${ }^{57}$ Furthermore, the sensitivity toward electrostatic discharge was evaluated. For every parameter, the 1-in-6 method was applied to determine the lowest energy or force needed for an ignition. The data are summarized in Table 2 . Conclusively, a classification of the compounds according to the UN Recommendation on the Transport of Dangerous Goods was made..$^{58}$

Because the primary goal here was to find a substitute for lead azide (LA), its sensitivity data are also listed in Table 2 . A comparison of the impact sensitivity with lead azide shows that the complexes presented in this work are for the most part more sensitive. However, this is irrelevant, since both LA as well as the copper azide ECCs are extremely sensitive materials and the danger of the substances is primarily due to their sensitivity toward friction and electrostatic discharge. Thus, similar sensitivity results were observed for the copper complexes of this work, and lead azide $(\mathrm{LA} \leq 0.1 \mathrm{~N}) .^{59}$

Measurements of friction sensitivity below $5 \mathrm{~N}$ were not performed in most cases. This is mainly due to the fact that a more precise determination in this range is usually less significant. In general, a friction sensitivity of below $5 \mathrm{~N}$ is already considered as extremely sensitive.

The only exceptions to this pattern are the compounds 3 $(\mathrm{IS}=10 \mathrm{~J}, \mathrm{FS}>360 \mathrm{~N})$ and $4(\mathrm{IS}=15 \mathrm{~J}, \mathrm{FS}>360 \mathrm{~N})$. The reason for this is difficult to explain. Both complexes are the only ones to show a distinct green colour. Furthermore, their crystal structure exhibits a unique coordination behaviour of an azido ligand, which coordinates in each case only simply via a nitrogen atom. Furthermore, the hydrate water in $\mathbf{4}$ leads to further desensitization.

It should also be noted that the majority of the ECCs in this work, analogous to lead azide, require an extremely low electrostatic discharge energy for ignition, which on the one hand facilitates ignition in detonators by electrostatic discharge, but on the other hand makes extreme caution necessary when handling these substances. The classification according to the UN Recommendation on the Transport of dangerous goods also results in the category extremely sensitive for all substances, except 3 and $\mathbf{4}$. The remaining substances are considered sensitive only. ${ }^{58,66}$

\section{Lead azide replacement suitability evaluation}

In the following the suitability of selected ECCs to replace LA was investigated. The compounds $1,3,4$, and 7 examined further because they either exhibited poor thermal stability or poor performance in the sensitivity measurements, indicating a distinct lack of performance. This assumption is based on the observation that primary explosives are only sufficiently suitable below a certain sensitivity threshold ${ }^{67}$ The definition of a primary explosive here results from the position of the compound in the initiation chain. Consequently, an energetic material should be able to initiate a booster explosive such as pentaerythritol tetranitrate (PETN) to be classified as a primary explosive. ${ }^{67}$

An important property of a suitable primary explosive is the deflagration to detonation transition (DDT) of a compound. ${ }^{67}$ In order to gain insight into this behaviour, hot plate and especially hot needle tests are performed with the respective substances. To perform the hot plate tests the evaluated substance is placed on a copper plate and subsequently heated with a Bunsen burner until a conversion was observed (Fig. 20, left). Especially the behaviour of the compound under fast heating is investigated with this experiment. Hot needle tests on the other hand, are carried out to investigate the substances' reaction when ignited under slight confinement. Therefore, the complex is taped to a copper plate with adhesive tape and penetrated with a red glowing needle subsequently (Fig. 20, right).

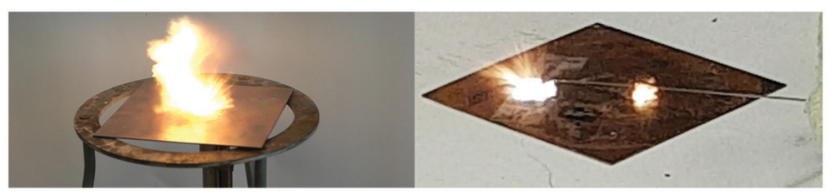

Fig. 20 Detonation of compound $\mathbf{5 a}$ during hot plate test (right side) and detonation of complex 10 (left side). 
Table 3 Results of hot plate and hot needle tests together with PETN initiation experiments of the compounds $\mathbf{5 a}$, 6a, and $\mathbf{9 - 1 3}$

\begin{tabular}{|c|c|c|c|c|c|c|c|c|c|}
\hline \multirow[b]{2}{*}{ Compound } & & \multirow[b]{2}{*}{$\mathrm{HP}^{a}$} & \multirow[b]{2}{*}{$\mathrm{HN}^{a}$} & \multirow[b]{2}{*}{ PETN initiation } & \multicolumn{4}{|c|}{ Laser ignition energy $^{b}$} & \multirow{2}{*}{$\begin{array}{l}\text { Detonation velocity } \\
{\left[\mathrm{km} \mathrm{s}^{-1}\right]}\end{array}$} \\
\hline & & & & & $0.17 \mathrm{~mJ}$ & $0.20 \mathrm{~mJ}$ & $1.7 \mathrm{~mJ}$ & $25.5 \mathrm{~mJ}$ & \\
\hline$\left[\mathrm{Cu}_{2}\left(\mathrm{~N}_{3}\right)_{4}(\mathrm{BTRI})\right]$ & $5 \mathbf{a}$ & det. & det. & positive & - & det. & - & - & 8.28 \\
\hline$\left[\mathrm{Cu}_{4}\left(\mathrm{~N}_{3}\right)_{8}(2-\mathrm{MAT})_{2}\right]$ & 9 & det. & det. & positive & - & - & det. & det. & 8.02 \\
\hline$\left[\mathrm{Cu}_{4}\left(\mathrm{~N}_{3}\right)_{8}(2,2-\mathrm{dte})\right]$ & 10 & det. & det. & positive & - & det. & - & - & 8.07 \\
\hline$\left[\mathrm{Cu}_{2}\left(\mathrm{~N}_{3}\right)_{4}(1,2-\mathrm{dtp})\right]$ & 11 & det. & det. & positive & det. & - & det. & - & 7.90 \\
\hline$\left[\mathrm{Cu}_{4}\left(\mathrm{~N}_{3}\right)_{8}(2,2-\mathrm{dtp})\right]$ & 12 & det. & det. & positive & det. & - & - & - & 7.83 \\
\hline
\end{tabular}

${ }^{a}$ defl.: deflagration; det.: detonation. ${ }^{b}$ Operating parameters: current $I=7-8$ A; voltage $U=4 \mathrm{~V}$; theoretical maximal output power $P_{\text {max }}=45 \mathrm{~W}$; theoretical energy $E_{\max }=0.17-25.5 \mathrm{~mJ}$; wavelength $\lambda=915 \mathrm{~nm}$; pulse length $\tau=1-15 \mathrm{~ms} .{ }^{c}$ Details can be found in the ESI.

In any case, the preferred test results are "detonations". The results are summarized in Table 3.

Due to the high detonation velocity of the remaining compounds, it was not possible to capture further images of the detonations during hot plate and hot needle tests with the setup used. However, these highly positive results enable testing the compounds in PETN initiation experiments. These studies provide further insight into the extent to which copper(II) azide ECCs are capable of replacing LA. For this purpose, $200 \mathrm{mg}$ of PETN was pressed into a copper shell and $50 \mathrm{mg}$ of the compound to be tested was loosely filled on top. Subsequently, the shell was placed on a copper witness plate and ignited with a type A electrical igniter. Parts of the setup are shown in Fig. 21. A positive DDT is indicated by a hole in the witness plate. Further details on the process and setup can be found in the ESI.+

For all of the compounds tested in this setup the initiation was positive (Table 3). This is quite impressive as these are more than half of the compounds presented in the work.

A positive initiation of compound $\mathbf{5 a}$ is exemplarily displayed in Fig. 21. Further images of the positive results can be found in the ESI.\$

Another feature of ECCs is laser ignitability. The field is attracting great interest, as it is anticipated that laser ignition will make mechanical ignition irrelevant. ${ }^{22,68-70}$ Therefore, an extreme sensitivity toward mechanical stimuli is no longer required for energetic materials and thus safe handling becomes easier.

The compounds presented in this work are not suitable insensitive laser ignitable substances as they are as sensitive as
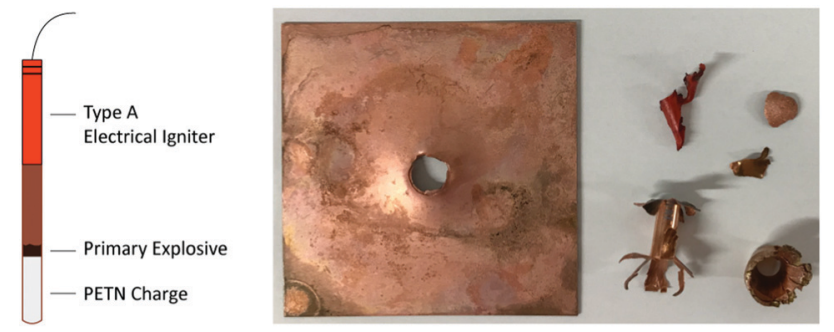

Fig. 21 Test setup for PETN Ignition experiments shown without the copper witness plate (left) and positive initiation experiment of compound 5a (right).

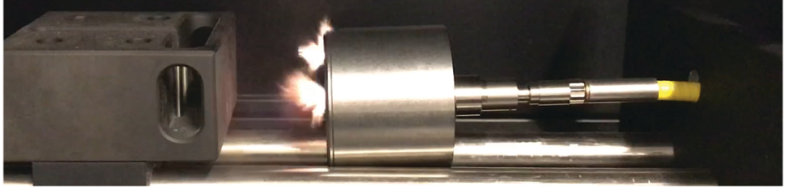

Fig. 22 Detonation of complex 9 during laser ignition experiments.

the cobalt perchlorate complex BNCP which they are supposed to replace. ${ }^{8}$ Nevertheless, the superior performance of the copper azide complexes, especially with respect to their simple synthesis and poor water solubility, makes a brief analysis of their behaviour in laser experiments interesting. The results of these experiments are displayed in Table 3. An example of a positive laser ignition result is shown in Fig. 22.

Further details on the laser setup can be found in the Supporting Information. As with the hot plate and hot needle tests, it was unfortunately not possible to record all detonations due to their high velocity. Overall, all complexes showed a reaction toward the laser irradiation. Interestingly the compounds 6a and 13 only showed deflagration, even at higher energies. This is particularly surprising because both compounds showed powerful detonations during preliminary hot plate and hot needle tests and successfully initiated PETN. Nevertheless, the majority of the coordination compounds

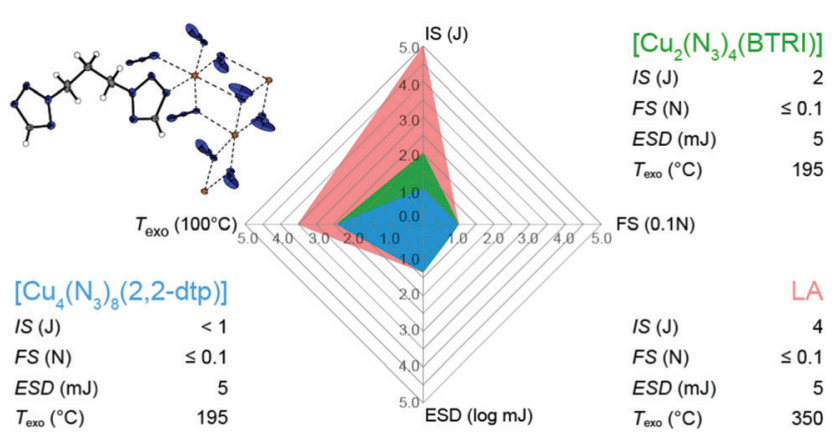

Fig. 23 Comparison of lead azide (LA) with the ECCs $\left[\mathrm{Cu}_{2}\left(\mathrm{~N}_{3}\right)_{4}(\mathrm{BTRI})\right](5 \mathrm{a})$ and $\left[\mathrm{Cu}_{4}\left(\mathrm{~N}_{3}\right)_{8}(2,2-\mathrm{dtp})\right]$ (12) in terms of thermal stability $\left(T_{\text {exo }}\right)$ and sensitivity toward friction (FS), impact (IS), and electrostatic discharge $(E S D)$. The friction sensitivity was only determined to $<5 \mathrm{~N}$ but is assumed to be within the range of LA. 
showed strong detonations at energies of $0.17-0.20 \mathrm{~mJ}$, again proving that copper azide complexes are powerful initiators in diverse application fields. Detonation velocities of the ECC was estimated according to a method, outlined in theESI. +

The experiments performed in this section demonstrate that the copper complexes in this work not only have the thermal stability and sensitivity, but also the required performance to successfully replace lead azide finally (Fig. 23).

\section{Conclusions}

In this work we have prepared 15 copper azide complexes based on nitrogen-rich triazole and tetrazole ligands. A special feature is the simple synthesis, which leads to a direct precipitation of the complexes. The poor water solubility drastically reduces the toxicity of the resulting complexes as well as enable their desensitization by moistening. The majority of the complexes was investigated using single crystal X-ray crystallography, unveiling unique coordination geometries caused by the interaction of azido ligands with tri- and tetrazoles. The main aim of this work was the stabilization of neat copper azide while keeping its useful properties like performance and thermal stability. This was achieved especially through the application of bridging ligands like BTRI, 2,2-dte, and 2,2-dtp with the resulting three-dimensional metalorganic frameworks exhibiting a thermal stability exceeding $190{ }^{\circ} \mathrm{C}$. Furthermore, PETN initiation tests have successfully demonstrated that the performance of copper azide has also been retained. Overall, the excellent initiation capability of these ECCs was not only shown in PETN initiation experiments, but also during laser ignition experiments. Consequently, the energetic coordination compounds presented in this work are worth considering as lead azide substitutes not only because of their simple synthesis, low toxicity, excellent thermal stability, but also because of their superior initiation ability.

\section{Author contributions}

The manuscript was written through contributions of all authors. All authors have given approval to the final version of the manuscript.

\section{Conflicts of interest}

There are no conflicts to declare.

\section{Acknowledgements}

For financial support of this work Ludwig Maximilian University of Munich (LMU) is gratefully acknowledged. The authors would like to thank Professor Dr Thomas M. Klapötke for his scientific support as well as for providing his research facilities. Furthermore, the authors would like to thank Benjamin Bissinger, Marina Schönherr, and Lukas Zeisel for their great contribution to this work.

\section{Notes and references}

1 H. H. Jobelius and H.-D. Scharff, Ullmann's Encyclopedia of Industrial Chemistry, Wiley-VCH, Weinheim, 6th edn, 2002.

2 M. Breugst and H.-U. Reissig, The Huisgen Reaction: Milestones of the 1,3-Dipolar Cycloaddition, Angew. Chem., Int. Ed., 2020, 59, 12293-12307.

3 H. C. Kolb, M. G. Finn and K. B. Sharpless, Click Chemistry: Diverse Chemical Function from a Few Good Reactions, Angew. Chem., Int. Ed., 2001, 40, 2004-2021.

$4 \mathrm{H}$. Staudinger and J. Meyer, Über neue organische Phosphorverbindungen III. Phosphinmethylenderivate und Phosphinimine, Helv. Chim. Acta, 1919, 2, 635-646.

5 J. Haase, in Organic Azides, ed. S. Bräse and K. Banert, John Wiley \& Sons, Ltd, Hoboken, New Jersey, 2009, pp. 29-51.

6 J. J. Jobelius and H.-D. Scharff, Ullmann's Encyclopedia of Industrial Chemistry, Wiley VCH, Weinheim, 7th edn, 2012.

7 H. D. Fair and R. F. Walker, in Physics and Chemistry of the Inorganic Azides, ed. H. D. Fair and R. F. Walker, Plenum Press, New York, 1st edn, 1977, vol. 1.

8 R. Matyás and J. Pachman, Primary Explosives, Springer Verlag, Berlin, 2013.

9 P. J. Landrigan, C. B. Schechter, J. M. Lipton, M. C. Fahs and J. Schwartz, Environmental pollutants and disease in American children: estimates of morbidity, mortality, and costs for lead poisoning, asthma, cancer, and developmental disabilities, Environ. Health Perspect., 2002, 110, 721-728.

10 A. D. Woolf, R. Goldman and D. C. Bellinger, Update on the Clinical Management of Childhood Lead Poisoning, Pediatr. Clin. North Am., 2007, 54, 271-294.

11 R. Hagel and K. Redecker, Sintox - A New, Non-Toxic Primer Composition by Dynamit Nobel AG, Propellants, Explos., Pyrotech., 1986, 11, 184-187.

12 C. He and J. M. Shreeve, Potassium 4,5-Bis(dinitromethyl) furoxanate: A Green Primary Explosive with a Positive Oxygen Balance, Angew. Chem., Int. Ed., 2016, 55, 772-775.

13 W. Huang, Y. Tang, G. H. Imler, D. A. Parrish and J. M. Shreeve, Nitrogen-Rich Tetrazolo[1,5-b]pyridazine: Promising Building Block for Advanced Energetic Materials, J. Am. Chem. Soc., 2020, 142, 3652-3657.

14 J. W. Fronabarger, M. D. Williams, W. B. Sanborn, J. G. Bragg, D. A. Parrish and M. Bichay, DBX-1 - A Lead Free Replacement for Lead Azide, Propellants, Explos., Pyrotech., 2011, 36, 541-550.

15 J. Tang, D. Chen, G. Zhang, H. Yang and G. Cheng, A “Green” Primary Explosive: Design, Synthesis, and Testing, Synlett, 2019, 885-892.

16 M. L. Gettings, M. T. Thoenen, E. F. C. Byrd, J. J. Sabatini, M. Zeller and D. G. Piercey, Tetrazole Azasydnone $\left(\mathrm{C}_{2} \mathrm{~N}_{7} \mathrm{O}_{2} \mathrm{H}\right)$ And Its Salts: High-Performing Zwitterionic Energetic Materials Containing A Unique Explosophore, Chem. - Eur. J., 2020, 26, 14530-14535.

17 L. M. Foroughi, R. A. Wiscons, D. R. Du Bois and A. J. Matzger, Improving stability of the metal-free primary energetic cyanuric triazide (CTA) through cocrystallization, Chem. Commun., 2020, 56, 2111-2114. 
18 L. Havlíková, R. Matyáš, L. Ihnát, L. Nováková and D. Šatínský, Degradation study of nitroaromatic explosives 2-diazo-4,6-dinitrophenol and picramic acid using HPLC and UHPLC-ESI-MS/MS, Anal. Methods, 2014, 6, 4761-4768.

19 J. W. Fronabarger, M. D. Williams, A. G. Stern and D. A. Parrish, MTX-1 - a potential replacement for tetrazene in primers, Cent. Eur, J. Energ. Mater., 2016, 13, 33-52.

20 M. Joas, T. M. Klapötke and N. Szimhardt, Photosensitive Metal(II) Perchlorates with 1,2-Bis[5-(1-methylhydrazinyl)tetrazol1-yl] ethane as Ligand: Synthesis, Characterization and Laser Ignition, Eur. J. Inorg. Chem., 2014, 493-498.

21 Z. Mi, S. Chen, Z. Jing, L. Yang and T. Zhang, Innovative Concept of Designing Primary Explosives by IntroducingPolymers: Preparation and Investigation of $\{[\mathrm{Ca}(\mathrm{CHZ}) 2](\mathrm{ClO} 4) 2\} \mathrm{n}$ (CHZ = carbohydrazide), Eur. J. Inorg. Chem., 2016, 3978-3983.

22 T. W. Myers, J. A. Bjorgaard, K. E. Brown, D. E. Chavez, S. K. Hanson, R. J. Scharff, S. Tretiak and J. M. Veauthier, Energetic Chromophores: Low-Energy Laser Initiation in Explosive Fe(II) Tetrazine Complexes, J. Am. Chem. Soc., 2016, 138, 4685-4692.

23 M. H. V. Huynh, M. D. Coburn, T. J. Meyer and M. Wetzler, Green primary explosives: 5-Nitrotetrazolato-N2-ferrate hierarchies, Proc. Natl. Acad. Sci. U. S. A., 2006, 103, 10322-10327.

24 Q. Zhang and J. M. Shreeve, Metal-Organic Frameworks as High Explosives: A New Concept for Energetic Materials, Angew. Chem., Int. Ed., 2014, 53, 2540-2542.

25 J.-G. Xu, X.-Z. Li, H.-F. Wu, F.-K. Zheng, J. Chen and G.C. Guo, Substitution of Nitrogen-Rich Linkers with Insensitive Linkers in Azide-Based Energetic Coordination Polymers toward Safe Energetic Materials, Cryst. Growth Des., 2019, 19, 3934-3944.

26 R. Haiges, R. J. Buszek, J. A. Boatz and K. O. Christe, Preparation of the First Manganese(III) and Manganese(Iv) Azides, Angew. Chem., Int. Ed., 2014, 53, 8200-8205.

27 R. Haiges, P. Deokar and K. O. Christe, Coordination Adducts of Niobium(v) and Tantalum(v) Azide M(N3)5 (M $=\mathrm{Nb}, \mathrm{Ta})$ with Nitrogen Donor Ligands and their SelfIonization, Angew. Chem., Int. Ed., 2014, 53, 5431-5434.

28 R. Haiges, J. Skotnitzki, Z. Fang, D. A. Dixon and K. O. Christe, The Molybdenum(v) and Tungsten(vi) Oxoazides $\left[\mathrm{MoO}\left(\mathrm{N}_{3}\right)_{3}\right],\left[\mathrm{MoO}\left(\mathrm{N}_{3}\right)_{3} \cdot 2 \mathrm{CH}_{3} \mathrm{CN}\right],\left[(\right.$ bipy $\left.) \mathrm{MoO}\left(\mathrm{N}_{3}\right)_{3}\right]$, $\left[\mathrm{MoO}\left(\mathrm{N}_{3}\right)_{5}\right] 2-,\left[\mathrm{WO}\left(\mathrm{N}_{3}\right)_{4}\right]$, and $\left[\mathrm{WO}\left(\mathrm{N}_{3}\right)_{4} \cdot \mathrm{CH}_{3} \mathrm{CN}\right]$, Angew. Chem., Int. Ed., 2015, 54, 15550-15555.

29 M. H. H. Wurzenberger, M. Lommel, M. S. Gruhne, N. Szimhardt and J. Stierstorfer, Refinement of Copper(II) Azide with 1-Alkyl-5H-tetrazoles: Adaptable Energetic Complexes, Angew. Chem., Int. Ed., 2020, 59, 12367-12370.

30 H. Zöllner, M. Joas, R. Schirra and K. Kaplan, Lead-free initiating agents or initiating agent mixtures, WO Pat., WO 2018011134A1, 2018.

31 T. M. Klapötke, J. Stierstorfer, M. H. H. Wurzenberger and N. Szimhardt, Use of a copper(II) azide complex as a primary explosive, WO Pat., 2019134867A1, 2019.

32 A. Cirulis, Das Kupferazid und dessen Komplexe, Naturwissenschaften, 1939, 27, 583.
33 Z.-G. Gu, J.-L. Zuo and X.-Z. You, A three-dimensional ferromagnet based on linked copper-azido clusters, Dalton Trans., 2007, 4067-4072.

34 S. Mukherjee and P. S. Mukherjee, CuII-azide polynuclear complexes of $\mathrm{Cu} 4$ building clusters with Schiff-base coligands: synthesis, structures, magnetic behavior and DFT studies, Dalton Trans., 2013, 42, 4019-4030.

35 Y.-B. Xie, L. Gan, E. Carolina Sañudo, H. Zheng, J. Zhao, M. Zhao, B. Wang and J.-R. Li, Tetrazolate-azido-copper(II) coordination polymers: tuned synthesis, structure, and magnetic properties, CrystEngComm, 2015, 17, 4136-4142.

36 X. Qu, L. Zhai, B. Wang, Q. Wei, G. Xie, S. Chen and S. Gao, Copper-based energetic MOFs with 3-nitro-1H-1,2,4triazole: solvent-dependent syntheses, structures and energetic performances, Dalton Trans., 2016, 45, 17304-17311.

37 B.-D. Wu, Y.-G. Bi, F.-G. Li, L. Yang, Z.-N. Zhou, J.-G. Zhang and T.-L. Zhang, A Novel Stable High-Nitrogen Energetic Compound: Copper(II) 1,2-Diaminopropane Azide, Z. Anorg. Allg. Chem., 2014, 640, 224-228.

38 J. Zhang, Y. Du, K. Dong, H. Su, S. Zhang, S. Li and S. Pang, Taming Dinitramide Anions within an Energetic MetalOrganic Framework: A New Strategy for Synthesis and Tunable Properties of High Energy Materials, Chem. Mater., 2016, 28, 1472-1480.

39 M. H. H. Wurzenberger, M. S. Gruhne, M. Lommel, N. Szimhardt, T. M. Klapötke and J. Stierstorfer, Comparison of 1-Ethyl-5 $\mathrm{H}$-tetrazole and 1-Azidoethyl-5 $\mathrm{H}$-tetrazole as Ligands in Energetic Transition Metal Complexes, Chem. Asian J., 2019, 14, 2018-2028.

40 M. H. H. Wurzenberger, S. M. J. Endraß, M. Lommel, T. M. Klapötke and J. Stierstorfer, Comparison of 1-Propyl$5 \mathrm{H}$-tetrazole and 1-Azidopropyl-5 $\mathrm{H}$-tetrazole as Ligands for Laser Ignitable Energetic Materials, ACS Appl. Energy Mater., 2020, 3, 3798-3806.

41 P. J. van Koningsbruggen, Y. Garcia, O. Kahn, L. Fournès, H. Kooijman, A. L. Spek, J. G. Haasnoot, J. Moscovici, K. Provost, A. Michalowicz, F. Renz and P. Gütlich, Synthesis, Crystal Structure, EXAFS, and Magnetic Properties of Catena [ $\mu$-Tris(1,2-bis(tetrazol-1-yl)propane-N1,N1')iron(II)]

Bis(perchlorate). First Crystal Structure of an Iron(II) SpinCrossover Chain Compound, Inorg. Chem., 2000, 39, 1891-1900.

42 N. Szimhardt, M. H. H. Wurzenberger, L. Zeisel, M. S. Gruhne, M. Lommel, T. M. Klapötke and J. Stierstorfer, 1-AminoTriazole Transition-Metal Complexes as Laser-Ignitable and Lead-Free Primary Explosives, Chem. - Eur. J., 2019, 25, 1963-1974.

43 N. Szimhardt, M. H. H. Wurzenberger, T. M. Klapötke, J. T. Lechner, H. Reichherzer, C. C. Unger and J. Stierstorfer, Highly functional energetic complexes: stability tuning through coordination diversity of isomeric propyllinked ditetrazoles, J. Mater. Chem. A, 2018, 6, 6565-6577.

44 F. Lu, E. Wang, J. Huang, M. Huang, F. Nie and F.-X. Chen, The synthesis, property and reduction of high-nitrogen compound 3,3',5,5'-tetraazido-4,4'-bis(1,2,4-triazole), Polyhedron, 2016, 117, 445-452. 
45 R. A. Henry and W. G. Finnegan, Mono-alkylation of Sodium 5-Aminotetrazole in Aqueous Medium, J. Am. Chem. Soc., 1954, 76, 923-926.

46 R. G. Child, A new synthesis of 3,4,5-triamino-4H-1,2,4-triazole (guanazine), Synthesis and structure of $\{[\mathrm{Zn}(1,2-\mathrm{di}(1,2,3,4-$ tetrazol-2-yl)ethane)3](ClO4)2\}n. The first coordination polymer based on 2-substituted tetrazole, J. Heterocycl. Chem., 1965, 2, 98-99.

47 R. Bronisz, Synthesis and structure of $\{[\operatorname{Zn}(1,2-\operatorname{di}(1,2,3,4-$ tetrazol-2-yl)ethane $\left.\left.)_{3}\right]\left(\mathrm{ClO}_{4}\right)_{2}\right\}_{\mathrm{n}}$. The first coordination polymer based on 2-substituted tetrazole, Inorg. Chim. Acta, 2002, 340, 215-220.

48 ESI†.

49 R. C. Seccombe and C. H. L. Kennard, Bonding in 1,2,4triazoles. Part II. Crystal structure of 3,4,5-triamino-1,2,4triazole hydrobromide (guanazine hydrobromide), J. Chem. Soc., Perkin Trans. 2, 1973, 1-3.

$50 \mathrm{~J}$. Bryden, The crystal structure of 2-methyl-5aminotetrazole, Acta Crystallogr., 1956, 9, 874-878.

51 M. Aouial, P. Viallefont and L. El Ammari, Etude conformationnelle du bi(triazole-1,2,4)-3,4', Acta Crystallogr., Sect. C: Cryst. Struct. Commun., 1991, 47, 1866-1868.

$52 \mathrm{~J}$. Bryden, The unit-cell dimensions and space groups of some tetrazole compounds, Acta Crystallogr., 1953, 6, 669-670.

53 M. Daszkiewicz and M. K. Marchewka, Crystal structure, vibrational and theoretical studies of bis(4-amino-1,2,4triazolium) hexachloridostannate(Iv), J. Mol. Struct., 2012, 1017, 90-97.

54 G. Kaplan, G. Drake, K. Tollison, L. Hall and T. Hawkins, Synthesis, characterization, and structural investigations of 1-amino-3-substituted-1,2,3-triazolium salts, and a new route to 1-substituted-1,2,3-triazoles, J. Heterocycl. Chem., 2005, 42, 19-27.

55 R. Soderquist, Studies on explosives. I. The crystal structure of copper(II) oxide, catena-diazidocopper(II), Acta Crystallogr., Sect. B: Struct. Crystallogr. Cryst. Chem., 1968, 24, 450-455.

56 M. S. Gruhne, M. H. H. Wurzenberger, M. Lommel and J. Stierstorfer, A Smart Access to the Dinitramide Anion The Use of Dinitraminic Acid for the Preparation of Energetic Coordination Compounds, Chem. - Eur. J., 2021, 27, 9112-9123.
57 BAM, www.bam.de, accessed June, 2021.

58 UN Model Regulation: Recommendations on the Transport of Dangerous Goods - Manual of Tests and Criteria, section 13.4.2.3.3, 2015.

59 M. S. Gruhne, M. Lommel, M. H. H. Wurzenberger, N. Szimhardt, T. M. Klapötke and J. Stierstorfer, OZM Ball Drop Impact Tester (BIT-132) vs. BAM Standard Method - a Comparative Investigation, Propellants, Explos., Pyrotech., 2020, 45, 147-153.

60 T. M. Klapötke, Energetic materials Encyclopedia, DeGruyter, Berlin, Boston, 2nd edn, 2021.

61 NATO standardization agreement (STANAG) on explosives, impact sensitivity tests, no. 4489, 1st edn., Sept. 17th, 1999.

62 WIWEB-Standardarbeitsanweisung 4-5.1.02, Ermittlung der Explosionsgefährlichkeit, hier der Schlagempfindlichkeit mit dem Fallhammer, Nov. 8th, 2002.

63 OZM Research, www.ozm.cz/en, accessed June, 2021.

64 NATO standardization agreement (STANAG) on explosive, friction sensitivity tests, no. 4487, 1st edn., Aug. 22nd, 2002.

65 WIWEB-Standardarbeitsanweisung 4-5.1.03, Ermittlung der Explosionsgefährlichkeit oder der Reibeempfindlichkeit mit dem Reibeapparat, Nov. 8th, 2002.

66 Impact: insensitive $>40 \mathrm{~J}$, less sensitive $\geq 35 \mathrm{~J}$, sensitive $\geq$ $4 \mathrm{~J}$, very sensitive $\leq 3 \mathrm{~J}$; Friction: insensitive $>360 \mathrm{~N}$, less sensitive $=360 \mathrm{~N}$, sensitive $<360 \mathrm{~N}$ and $>80 \mathrm{~N}$, very sensitive $\leq 80 \mathrm{~N}$, extremely sensitive $\leq 10 \mathrm{~N}$. According to the UN Recommendations on the Transport of Dangerous Goods, 5th edn, 2009.

67 T. M. Klapötke, Chemistry of High-Energy Materials, De Gruyter, Berlin, Boston, 5th edn, 2019.

68 T. W. Myers, K. E. Brown, D. E. Chavez, R. J. Scharff and J. M. Veauthier, Laser Initiation of Fe(II) Complexes of 4-Nitro-pyrazolyl Substituted Tetrazine Ligands, Inorg. Chem., 2017, 56, 2297-2303.

69 A. Y. Zhilin, M. A. Ilyushin, I. V. Tselinskii, A. S. Kozlov and I. S. Lisker, High-Energy-Capacity Cobalt(III) Tetrazolates, Russ. J. Appl. Chem., 2003, 76, 572-576.

70 M. A. Ilyushin, A. S. Tver'yanovich, Y. S. Tver'yanovich, G. O. Abdrashitov, A. O. Aver'yanov and M. D. Bal'makov, Laser Initiation of Photo- and Thermal Processes on a Pentaammine (5-Nytrotetrazolato- $\mathrm{N}_{2}$ ) Cobalt(III) Perchlorate Example, Glass Phys. Chem., 2018, 44, 120-122. 